\title{
Efficient Approaches to Optimize Energy Consumption in 3D Wireless Video Sensor Network under the Coverage and Connectivity Constraints
}

Kishalay Bairagi ( $\sim$ kishalayb29@gmail.com )

IIEST Shibpur: Indian Institute of Engineering Science and Technology https://orcid.org/0000-00024676-3332

\section{Sulata Mitra}

IIEST Shibpur: Indian Institute of Engineering Science and Technology

Uma Bhattacharya

IIEST Shibpur: Indian Institute of Engineering Science and Technology

\section{Research Article}

Keywords: 3D Video Sensor Nodes, 2D Target Area, Random Deployment, AGA, ILP, Energy Consumption, Area Coverage, Connectivity

Posted Date: January 25th, 2022

DOI: https://doi.org/10.21203/rs.3.rs-1061729/v1

License: (1) (i) This work is licensed under a Creative Commons Attribution 4.0 International License. Read Full License 


\title{
Efficient Approaches to Optimize Energy Consumption in 3D Wireless Video Sensor Network under the Coverage and Connectivity Constraints
}

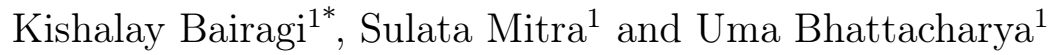 \\ ${ }^{1 *}$ Department of Computer Science \& Technology, IIEST Shibpur, \\ Botanical Garden Rd, Howrah, 711103, West Bengal, India.
}

*Corresponding author(s). E-mail(s): kishalayb29@gmail.com;

\begin{abstract}
Two advanced approaches (PA_1, and PA_2) based on a realistic 3D model of video sensor nodes ( $\mathrm{VS} N s)$ deployed over a $2 \mathrm{D}$ target area are proposed to minimize energy consumption in the network maintaining area coverage and connectivity. Reducing the number of active VSNs decreases energy consumption, but lessens area coverage and connectivity too. These conflicting issues are resolved and an optimal solution is obtained by using an integer linear programming based approach PA_1. The problem being an NP-Hard one, PA_1 is not tractable for large instances, and a heuristic PA_2 based on an advanced genetic algorithm, is also developed to obtain the near-optimal solution. Simulation studies are carried out to compare the performance of PA_1, and PA_2 with the other three state-of-the-art approaches $\left(\mathrm{APP} \_5, \mathrm{APP}_{-} 6\right.$, and $\left.\mathrm{ET} \_3\right)$. Among three existing approaches, APP_6/(ET_3) is the best in energy consumption/(area coverage). It is observed that for the same simulation environment, both PA_1, and PA_2 guarantee higher network services, by reducing energy consumption by $40.85 \%$ and $33.34 \%$ respectively compared to the best existing approach APP _6; and as well as by increasing area coverage by $0.94 \%$ than the best existing approach ET_3 for the node density 150 on the target area of size $75 \times 75$ square meter. Between PA_1 and PA_2, PA_2 generates sub-optimal solution and PA_1 substantiates its superiority by reducing energy consumption by $11.2 \overline{6} \%$ than PA_2 without losing area coverage for the same simulation environment.
\end{abstract}


Keywords: 3D Video Sensor Nodes, 2D Target Area, Random Deployment, AGA, ILP, Energy Consumption, Area Coverage, Connectivity

\section{Introduction}

A set of video sensor nodes (VSNs) furnished with miniature video cameras called CMOS [14] cameras forms a wireless video sensor network (WVSN). Such sensors possess the function of capturing video and image and are extensively utilized in various applications like surveillance work, monitoring in the affected area with natural disasters, tracking, environment monitoring etc. Operational by limited battery power, WVSN exhibits its challenging attitude in the profile of energy consumption as in almost all the cases the battery is not rechargeable, nor it is replaceable. Such VSNs can exhaust energy rapidly owing to constant sensing and transmission of video data. It lowers both monitoring quality and network lifetime.

The WVSN generally operates in an unfriendly environment, which requires VSNs to be deployed randomly with high density to ensure smooth working of the application even if a few VSNs fail. But such densely deployed VSNs generate huge overlapping of coverage in the target area. The scheduling schemes of [1-9] utilize such overlapping coverage to cover the sensing area/region of a VSN and to shut such VSNs off for lowering the number of active VSNs which results into reduction of energy consumption in the target area, without losing the percentage of initial area coverage by the VSNs significantly (termed as coverage constraint). But, the minimization (optimization) of the number of active VSNs (or, minimization of energy consumption by the active VSNs) are not addressed in [1-9]. Moreover, the connectivity among VSNs and between VSN and the base station (BS) (termed as connectivity constraints) are not addressed in [1-9]. The issue of minimizing the number of active VSNs (or, energy consumption in the target area) while satisfying coverage constraint and also connectivity constraint is addressed by proposing new approaches (PA_1, PA_2) in this work. Both the approaches use the 3D coverage model

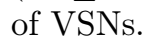

PA 1 uses a single-objective optimization technique Integer Linear Program (ILP) for a system of linear constraints, with the objective to minimize the total number of active 3D VSNs for a particular random distribution of 3D VSNs. ILP generates optimal solution but is intractable for large instances as the problem is NP-Hard [10]. PA_2, a heuristic approach being based on the Advanced Genetic Algorithm (AGA)[11, 12] solves the same problem to produce the near-optimal solution, which runs in polynomial time and provide the solution for a large problem size.

A single base station (BS) is set up by the side of the target area both in PA_1 and PA_2 and the location of the BS in the target area is supplied to all the VSNs before their deployment. The BS is connected to WVSN via some VSNs that are inside the communication range of the BS. Each VSN in both 
approaches executes the neighbour discovery phase, registration phase and duty cycling phase sequentially in the target area. In the neighbour discovery phase, each VSN identifies the position and also orientation of its neighbour VSNs by exchanging messages among themselves. It then inserts such neighbour information in a neighbour table both in PA_ 1 and PA_2. In the phase of registration, each VSN in both $\mathrm{PA}_{-} 1$ and $\mathrm{PA}_{-} 2$ transmits its position and orientation for itself to the BS. The BS inserts such type of information into a table named a base table (BT). During the duty cycling phase, the BS in PA_1/PA_2 executes a centralized algorithm. The centralized algorithm is $\operatorname{ILP} /\left(\mathrm{AGA}_{\overline{\mathrm{A}}}\right)$ based for PA_1/(PA_2). The BS identifies an optimal/(nearoptimal) number of active VSNs and sends a sleep message to all the identified VSNs for shutting them off. Such VSNs then enter sleep mode.

The performances of $\mathrm{PA}_{-} 1$ and $\mathrm{PA} \_2$ are compared with the three existing approaches, APP_5[14], APP_6[14] and ET_3 (upgraded 3D version of [13]). ET 3 are evolved by replacing 2 D VSNs with $3 \mathrm{D}$ VSNs.

The qualitative and quantitative performance of both approaches is studied. The qualitative performance is assessed considering communication, storage and computation overhead. The quantitative performance is studied during simulation by noting the variation of the number of active 3D VSNs (Act_VSN), total energy consumption by the set of active VSNs $\left(\mathrm{E}_{\text {Tot }}\right)$, total residual energy $\left(\mathrm{E}_{\text {Res }}\right)$, percentage of area coverage by the set of active VSNs (Per_CoV) and network lifetime with the density of VSNs in the target area. The performances of $\mathrm{PA}_{-} 1$ and $\mathrm{PA}_{-} 2$ are compared with that of $\mathrm{APP}_{-} 5$, APP_6 and ET_3 both qualitatively and quantitatively.

It has been observed during simulation that the number of VSNs which are going into the sleep mode is optimum (maximum) in $\mathrm{PA}_{-} 1$ and hence, $\mathrm{PA}{ }_{-} 1$ performs much better with respect to energy consumption compared to PA_2, $\mathrm{APP}_{-} 5, \mathrm{APP}_{-} 6$ and $\mathrm{ET} \_3$. Both $\mathrm{PA}_{-} 1$ and $\mathrm{PA} \_2$ works with an objective to minimize energy consumption while considering connectivity constraint and coverage constraint. Both $\mathrm{PA}_{-} 1$ and $\mathrm{PA}_{-} 2$ reduce communication overhead compared to $\mathrm{APP}_{-} 5, \mathrm{APP}_{-} 6$ and $\mathrm{ET}_{-} 3$.

\section{The most important contributions of this paper are as provided below:}

- A practical coverage model of VSNs is explained by adopting 3D VSNs which are projected on a $2 \mathrm{D}$ plane surface.

- Then, ILP based optimization technique (PA_1) has been applied for getting an optimal value of the objective function which is the number of active $3 \mathrm{D}$ VSNs i.e. energy consumption subject to connectivity and coverage constraints. Coverage constraint assumes the value of area coverage to remain constant after the deployment of sensor nodes in the target area.

- The heuristic approach (PA_2) based on the optimization technique (AGA) is proposed for getting near-optimal values of the number of active 3D VSNs (or, energy consumption by all the active VSNs in the target area), subject to connectivity as well as coverage constraints.

In this paper, related works are provided in Section 2. The coverage model, network model and some definitions are discussed in Section 3. The model for 
energy consumption is provided in Section 4. Section 5 explains the proposed work. Section 6 examines the qualitative performance of $\mathrm{PA}_{-} 1, \mathrm{PA}_{-} 2$ and the existing works $\mathrm{APP}_{-} 5, \mathrm{APP}_{-} 6$ and ET_3, and Section 7 demonstrates simulation experiments and quantitative performance evaluation. Section 8 records observations related to the performance of PA 1 and PA 2. Section 9 deals with experimental analysis. Finally, Section $10 \overline{\mathrm{dr}}$ aws the conclusion of the paper and suggests the future scope followed by references.

\section{Related Work}

A distributed approach of duty-cycling technique is proposed in [2-9]. Each VSN produces two activity messages, specifying its active/inactive status, and send those two messages to its neighbours. The VSN sends one activity message to its neighbours when it is a deciding factor of whether to slip into sleep mode or to stay active. It sends the other activity message to its neighbours after deciding to stay active or to go into sleep mode. A huge message loss is caused during such transmission and reception, as no order is maintained. In [1], two duty cycling approaches $\left(\mathrm{APP}_{-} 1\right.$ and $\left.\mathrm{APP} \_2\right)$ are proposed. A mingling of a small percentage $(40 \%)$ of static active/inactive VSN (AIVSN) and a large percentage $(60 \%)$ of static all-time active VSN (ATVSN) are deployed in a random manner in the target area both in $\mathrm{APP}_{-} 1$ and $\mathrm{APP} \_2$. It is a significant development over the duty cycling approach as revealed in [2] and in other approaches [3-9]. Only AIVSNs in APP_1 and APP_2 take part in the duty cycling approach. This brings down collision among messages and as a result, more VSNs enter the sleep mode. But, both in $\mathrm{APP}_{-} 1$ and $\mathrm{APP} \_2$ only AIVSNs (40\% of total VSNs) are permitted to enter the sleep mode. Besides, all the approaches consider 2D modelling of sensing region/Field of View (FoV) of VSN. But, the 2D modelling of FoV does not indicate a realistic model for camera coverage. A novel scheduling algorithm among sensor nodes is suggested in [13]. The scheduling algorithm in [13] is based upon the redundancy among Wireless Sensor Nodes (WSNs). It is a hybrid algorithm (i.e.mingling of centralized and distributed) and grid-based for shutting off WSNs. But heuristics in [13] have used the 2D Omni-directional sensing model of WSNs, not a realistic camera coverage model. Two centralized approaches (APP_5 and APP _6) having an advanced duty-cycling technique are suggested in [14]]. These two approaches are successful in lowering the number of active VSNs, total energy consumption by the active VSNs more compared to the existing approaches (EX_1, EX_2, EX_3). EX_1, EX_2 and EX_3 are the upgraded $3 \mathrm{D}$ version of [1], [2] and [13] respectively as revealed in [14]. Consequently, the loss of coverage by the active VSNs is also more in [14] compared to EX_1, EX_2 and EX_3. But, the scheduling schemes in $[1-9,13,14]$ are able to reduce the number of active VSNs and in turn energy consumption at the cost of a reduction in the percentage of coverage. They fail to produce optimized (minimized) value of the number of active VSNs and energy consumption without losing area coverage. In order to gather images having visual correlation 
efficiently, a scheduling framework based on differential coding has been proposed in [15]. This framework is composed of two components which include Maximum Lifetime Scheduling and Min-Max Degree Hub Location. The proposed scheduling scheme based on differential coding can effectively enhance the energy efficiency of camera sensors and the network throughput. But, the problem of Maximum Lifetime Scheduling is an NP-Hard problem. In [16] two problems have been dealt with. One problem deals with the camera scheduling i.e. the selection of a set of cameras among available possibilities for allowing the required coverage at each instant of time. The second problem addresses the energy allocation i.e. how the total available energy is distributed among the camera sensor nodes. The problem of energy allocation is constructed as a min-max optimization problem that targets maximizing the coverage duration for the most critical region of the target area, where the availability of energy is the minimum. But min-max optimization problem being an NP-Hard problem can only be solved for the problem of small size. In [17] a real-time dynamic scheduling algorithm has been proposed based on priority for wireless multimedia sensor networks. The scheme in [17] doesn't possess any scheduling mechanism at the application level among VSNs and consequently, all VSNs stay in active mode. In [18] a scheduling algorithm based on priority has been suggested to increase the network lifetime. A mixture of static and movable VSNs has been used in [18]. As some VSNs are movable, it results in a huge wastage of energy. In [19] an optimal point of partitioning with intelligence between the central BS and the sensor node has been selected. Outcomes in [19] suggest that sending zipped images after segmentation increases the lifetime of the sensor node. But, there still remains a huge wastage of energy and data redundancy because all VSNs stay active both in $[17,19]$ in the target area. A two-phase algorithm is proposed in [20]. The Binary Integer Programming based algorithm is able to solve the problem of optimal camera placement for a placement space greater than that of the recent study. This study helps to solve the problem in three-dimensional space which is a more realistic scenario. A binary particle swarm optimization (BPSO) based algorithm is proposed in [21] for solving a planned placement problem of a homogeneous camera sensor network. But both [20, 21] deal with the deployment of VSNs in a planned way in the target area. In the post-disaster scenario, the planned deployment of camera sensors is not possible. Many works like [22-24, 27] deal with target coverage where sensor nodes are to cover few target points instead of the whole area of the target. But in a post-disaster scenario, the whole area needs to be monitored. A PSO collaborative evolution based sleep scheduling mechanism for WSN is proposed in [23]. A hierarchical structure prevails between the ordinary nodes and the backbone nodes in [23]. But such a hierarchical structure is unsuitable in the post-disaster scenario where the random deployment of sensor nodes is the only possibility. A PSO based sleep scheduling algorithm is proposed in [25]. The method used in [25] is able to bring down the number of active WSNs and energy consumption ensuring an adequate percentage of coverage. An improved immune fuzzy genetic algorithm (IIFGA) is suggested in 
[26] to remove redundancy among WSNs and to select a set of working WSNs without lowering the quality of the coverage much. Both [25, 26] lower the number of active WSNs in the target area though they are unable to produce an optimal (minimum) value of the number of active WSNs. Besides, the coverage model of 2D WSNs is used in [22-27]. Being Omni-directional (circular), the coverage model of a $2 \mathrm{D}$ WSN is very simple, but it cannot be implemented in reality.

Both the approaches (PA_1 and PA_2) which utilize the 3D coverage model of VSN is a more realistic model of camera coverage than the $2 \mathrm{D}$ coverage model of VSN as considered in [1-8] and 2D Omni-directional coverage model of WSN as considered in [13, 22-27]. Besides, the proposed approaches (PA_1 and PA_2) provide optimal and near-optimal values for the number of active VSNs and energy consumption respectively unlike $[1-9,13,14,17]$. Unlike [18], the usage of static VSN further minimizes energy consumption owing to the mobility of VSNs. PA_ 2 can run in polynomial time unlike $[15,16]$. All the VSNs do not stay active in the target area as present in $[17,19]$. Both the approaches (PA_1 and PA_2) shut off VSNs to optimize (minimize) the number of active VSNs and energy consumption in the duty cycling phase without losing coverage and hence, the same quantity of video data is collected with less data redundancy unlike in [17, 19]. The deployment of $3 \mathrm{D}$ VSNs in a random manner in the target area unlike [20,21] is suitable when it is difficult for the human being to reach first at the target area. Unlike [22-24, 27], in the present work, the whole area needs to be monitored and the motivation of the present work is to minimize the number of $3 \mathrm{D}$ active VSNs without losing initial area coverage which is the percentage of coverage when all VSNs were active. The approach $\mathrm{PA}_{-} 1 /\left(\mathrm{PA}_{-} 2\right)$ of the work proposed in this paper is able to minimize the number of active VSNs under the coverage and connectivity constraints unlike [25, 26], while PA_1/(PA_2) provides an optimal/(near-optimal) solution.

Proposed works and several very current related works are summed up in Table 1.

\section{Coverage Model, Network Model and Some Definitions}

\subsection{Coverage Model and Network Model}

In the present work, the coverage model and the network model are considered the same as described in [14], since the proposed approaches ( $\mathrm{PA}_{-} 1$ and PA_2), as well as all the existing approaches, follow the same coverage and network model. Fig. 3a in [14] shows the 3D directional sensing model of a VSN v. Fig. 3b and Fig. 3c in [14] show the Field of View (FoV) of the VSN $\mathrm{v}$ when it is projected on the target area, which is a $2 \mathrm{D}$ plane surface.

Additionally, the BS represents the target area (A) by some uniform random points to make the coverage problem computationally manageable. 
Table 1 Comparative Study among Proposed Works and Related Works

\begin{tabular}{|c|c|c|c|c|c|c|c|}
\hline Method & $\begin{array}{l}\text { Coverage } \\
\text { Model }\end{array}$ & $\begin{array}{l}\text { Coverage } \\
\text { Model }\end{array}$ & $\begin{array}{l}\text { FoV } \\
\text { Area }\end{array}$ & $\begin{array}{l}\text { Duty- } \\
\text { Cycling } \\
\text { Strategy }\end{array}$ & $\begin{array}{l}\text { Target } \\
\text { Area }\end{array}$ & $\begin{array}{l}\text { Optimization } \\
\text { Technique } \\
\text { Used }\end{array}$ & Objectives \\
\hline APP_5[14] & $\begin{array}{l}\text { Static } \\
\text { VSN }\end{array}$ & $\begin{array}{l}3 \mathrm{D} \\
\text { Directional }\end{array}$ & Trapezoidal & Centralized & $2 \mathrm{D}$ & No, Greedy & $\begin{array}{l}\text { Reduce } \mathrm{E}_{T o t}, \\
\text { Ensure } \\
\text { coverage } \\
\text { and } \\
\text { Connectivity }\end{array}$ \\
\hline APP_6[14] & $\begin{array}{l}\text { Static } \\
\text { VSN }\end{array}$ & $\begin{array}{l}\text { 3D } \\
\text { Directional }\end{array}$ & Trapezoidal & Centralized & $2 \mathrm{D}$ & No, Greedy & $\begin{array}{l}\text { Reduce } \mathrm{E}_{T o t} \text {, } \\
\text { Ensure } \\
\text { coverage } \\
\text { and } \\
\text { Connectivity }\end{array}$ \\
\hline $\mathrm{ET} \_1[1]$ & $\begin{array}{l}\text { Static } \\
\text { VSN }\end{array}$ & $\begin{array}{l}\text { 3D } \\
\text { Directional }\end{array}$ & Trapezoidal & Distributed & $2 \mathrm{D}$ & No, Greedy & $\begin{array}{l}\text { Reduce } \mathrm{E}_{T o t} \text {, } \\
\text { Ensure } \\
\text { coverage } \\
\text { and } \\
\text { Connectivity }\end{array}$ \\
\hline $\mathrm{ET} \_11[1]$ & $\begin{array}{l}\text { Static } \\
\text { VSN }\end{array}$ & $\begin{array}{l}\text { 3D } \\
\text { Directional }\end{array}$ & Trapezoidal & Distributed & $2 \mathrm{D}$ & No, Greedy & $\begin{array}{l}\text { Reduce } \mathrm{E}_{T o t} \text {, } \\
\text { Ensure } \\
\text { coverage } \\
\text { and } \\
\text { Connectivity }\end{array}$ \\
\hline $\mathrm{ET} \_2[2]$ & $\begin{array}{l}\text { Static } \\
\text { VSN }\end{array}$ & $\begin{array}{l}\text { 3D } \\
\text { Directional }\end{array}$ & Trapezoidal & Distributed & $2 \mathrm{D}$ & No, Greedy & $\begin{array}{l}\text { Reduce } \mathrm{E}_{\text {Tot }} \text {, } \\
\text { Ensure } \\
\text { coverage } \\
\text { and } \\
\text { Connectivity }\end{array}$ \\
\hline ET_3[13] & $\begin{array}{l}\text { Static } \\
\text { VSN }\end{array}$ & $\begin{array}{l}\text { 3D } \\
\text { Directional }\end{array}$ & Trapezoidal & Hybrid & $2 \mathrm{D}$ & No, Greedy & $\begin{array}{l}\text { Reduce } \mathrm{E}_{\text {Tot }} \text {, } \\
\text { Ensure } \\
\text { coverage } \\
\text { and } \\
\text { Connectivity }\end{array}$ \\
\hline $\mathrm{PA}_{-} 1$ & $\begin{array}{l}\text { Static } \\
\text { VSN }\end{array}$ & $\begin{array}{l}\text { 3D } \\
\text { Directional }\end{array}$ & Trapezoidal & Centralized & $2 \mathrm{D}$ & $\begin{array}{l}\text { Single-Objective, } \\
\text { ILP }\end{array}$ & $\begin{array}{l}\text { Minimize } \mathrm{E}_{T o t}, \\
\text { Ensure } \\
\text { coverage } \\
\text { and } \\
\text { Connectivity }\end{array}$ \\
\hline $\mathrm{PA} \_2$ & $\begin{array}{l}\text { Static } \\
\text { VSN }\end{array}$ & $\begin{array}{l}\text { 3D } \\
\text { Directional }\end{array}$ & Trapezoidal & Centralized & $2 \mathrm{D}$ & $\begin{array}{l}\text { Single-Objective, } \\
\text { AGA }\end{array}$ & $\begin{array}{l}\text { Minimize } \mathrm{E}_{T o t} \text {, } \\
\text { Ensure } \\
\text { coverage } \\
\text { and } \\
\text { Connectivity }\end{array}$ \\
\hline
\end{tabular}

Tot_Randpoints is the total number of random points created by the BS in the target area. The BS knows the position of Tot_Randpoints in the target area in $(\mathrm{x}, \mathrm{y})$ coordinates and stores such coordinates in a list, $\mathrm{L}_{\text {Rand }}$. 


\subsection{Some Definitions}

Definition 1: The mathematical structure of the general ILP formulation of single-objective optimization problem is as follows:

Optimize $\mathrm{F}^{\prime}\left(\operatorname{decs}_{1}\right.$, $\left.\operatorname{decs}_{2}, \ldots . . \operatorname{decs}_{n}\right)$

subject to $\mathrm{G}^{\prime}{ }_{\mathrm{j}^{\prime}}\left(\operatorname{decs}_{1}\right.$, $\left.\operatorname{decs}_{2}, \ldots \ldots \operatorname{decs}_{n}\right)(\leq /=/ \geq) 0,1 \leq \mathrm{j}^{\prime} \leq \mathrm{J}^{\prime}$

where

- $\mathrm{F}^{\prime}$ represents the objective function to be optimized

- $\left(\operatorname{decs}_{1}, \operatorname{decs}_{2}, \ldots . . \operatorname{decs}_{n}\right)$ are the $\mathrm{n}$ decision variables and $\operatorname{decs}_{n}$ is the $\mathrm{n}^{\text {th }}$ decision variable

- Furthermore, the problem is subjected to $\mathrm{J}^{\prime}$ number of inequality/equality constraints. $G^{\prime} j^{\prime}$ is the $j^{\text {th }}$ constraint

- Additionally, each decision variable has an upper and/or lower bound associated with it e.g. 1st decision variable $\left(\operatorname{decs}_{1}\right)$ has an upper and/or lower bound $\left(\operatorname{decs}_{1}(\mathrm{U})\right.$ and $/$ or $\left.\operatorname{decs}_{1}(\mathrm{~L})\right)$, 2nd decision variable $\left(\operatorname{decs}_{2}\right)$ has an upper and/or lower bound $\left(\operatorname{decs}_{2}{ }^{(\mathrm{U})}\right.$ and/or $\left.\operatorname{decs}_{2}(\mathrm{~L})\right)$, and so on. $\operatorname{decs}_{1}{ }^{(\mathrm{L})} \leq \operatorname{decs}_{1} \leq$ $\operatorname{decs}_{1}{ }^{(\mathrm{U})}, \operatorname{decs}_{2}{ }^{(\mathrm{L})} \leq \operatorname{decs}_{2} \leq \operatorname{decs}_{2}{ }^{(\mathrm{U})} \ldots . \operatorname{decs}_{n}{ }^{(\mathrm{L})} \leq \operatorname{decs}_{n} \leq \operatorname{decs}_{n}{ }^{(\mathrm{U})}$

Definition 2: Optimization of the objective function, either minimization or maximization.

Definition 3: The constraints and the objective function are the linear functions of these decision variables.

Definition 4: A set of values of decision variables $\left(\operatorname{decs}_{1}, \operatorname{decs}_{2}, \ldots . \operatorname{decs}{ }_{n}\right)$ is a solution.

Definition 5: A solution that satisfies the set of constraints and variable bounds is called a feasible solution. All feasible solutions form feasible decision space.

Definition 6: An optimal solution is a feasible solution that optimizes the objective function. The optimal solution produces the optimal value of the objective function.

\section{Energy Consumption Model}

In the present work, the model for energy consumption is the same as described in [14].

Calculation of energy consumption $\left(E_{T o t}\right)$ :

Let the definition of $\mathrm{E}_{\text {Tot }}$ be the total energy consumption by Act_VSN in Joule during the simulation time 0 to $\mathrm{t} \mathrm{s}$. $\mathrm{E}_{T o t}$ is calculated for only Act_ VSN. Let $\mathrm{E}_{v a}$ is the total energy consumption by the VSN $\mathrm{v}$ during the simulation time 0 to $\mathrm{t} \mathrm{s}$. Therefore, as stated by the model for energy consumption described in [14], $\mathrm{E}_{\text {Tot }}$ is calculated at simulation time $\mathrm{t} \mathrm{s}$ as ( $\mathrm{E}_{v a} \mathrm{x}$ Act_VSN) i.e.

$$
E_{\mathrm{Tot}}=E_{\mathrm{va}} X A c t_{-} V S N
$$

assuming, at the same time, i.e. at $\mathrm{t}=0$ all VSNs are deployed. 


\section{Present Work}

Both the approaches (PA_1, PA_2) are elaborated in this section. The three phases, neighbour discovery phase, registration phase and duty-cycling phase are executed by each VSN in the target area sequentially. PA_1 and PA_2 differ in the duty cycling phase. The neighbour discovery phase and the registration phase of PA_1 and PA_2 are the same and described in Section 1. In the registration phase, each VSN in the target area selects a route from itself to the BS using GPSR routing protocol with tunable MAC [28] which is utilized in multi-hop based routing.

\subsection{Duty Cycling Phase}

The BS in both approaches executes a centralized algorithm for duty cycling, coverage and connectivity control (DCC). $\mathrm{DCC}_{1} /\left(\mathrm{DCC}_{2}\right)$ are the $\mathrm{DCC}$ algorithm for $\mathrm{PA}_{-} 1 /\left(\mathrm{PA} \_2\right)$. Both in $\mathrm{DCC}_{1}$ and $\mathrm{DCC}_{2}$, the objective function $\left(\mathrm{Obj}_{\text {_F }}\right.$ which minimizes Act_VSN) depend on decision variables which are the status of VSNs. The BS formulates single objective optimization for the objective function and constraints in the ILP format before the execution of both $\mathrm{DCC}_{1}$ and $\mathrm{DCC}_{2}$ as shown below.

Min Obj_F $\left(\right.$ Status $_{1}$, Status $_{2}, \ldots \ldots$ Status $\left._{T} N\right)$

Subject to the following two constraints:

$$
\begin{gathered}
O b j_{-} F=A c t_{-} V S N=\sum^{\mathrm{T}_{-}{ }^{\mathrm{N}}{ }_{\mathrm{v}=1}\left(\text { Status }_{v}=1\right) \geq A c t_{-} V S N_{\min }} \\
P e r_{-} C o V \geq \text { Init_COV }_{-} \mathrm{C} h_{\text {coverage }}
\end{gathered}
$$

(where $\mathrm{Th}_{\text {coverage }}$ is the threshold value of percentage of area coverage [14]), Init_CoV is Per_CoV by Init_Ran which indicates the scenario after the initial random deployment of VSNs when all VSNs are in active mode. Act_ $\mathrm{VSN}_{\min }$ is the least number of active VSNs that cannot be shut off to satisfy the connectivity constraint. $\mathrm{T}_{-} \mathrm{N}$ is the total number of VSNs deployed in the target area.

Here, Obj_F is the proposed objective function. Status $v_{v}$ is the status of $\mathrm{v}^{\text {th }}$ VSN where $1 \leq \mathrm{v} \leq \mathrm{T}_{-} \mathrm{N}$ and $\operatorname{Status}_{v} \in(0,1)$. Status $_{1}, \operatorname{Status}_{2}, \ldots . . \operatorname{Status}_{T}{ }_{N}$ are the status of deployed VSNs and also the decision variables of the objective function. Act_VSN $\geq$ Act_ $\mathrm{VSN}_{\min }$ and Per_CoV $\geq$ Init_CoV $\geq \mathrm{Th}_{\text {coverage }}$ are the connectivity constraint and coverage constraint respectively that need to be satisfied. Act_ $\mathrm{VSN}_{\min }$ is the minimum number of active VSNs that cannot be shut off to satisfy the connectivity constraint. The value of Act_ $\mathrm{VSN}_{\text {min }}$ is calculated using Eq. 5[29].

$$
R_{c}=\sqrt{((1+\epsilon) \ln A /(\pi \lambda))}
$$

Here $\mathrm{R}_{c}$ is the communication range, $\lambda$ is the number of $3 \mathrm{D}$ VSNs per unit area and $\epsilon$ is a constant whose value lies between 0 and 0.5 . Now, $\lambda$ is 
calculated by considering $\epsilon=0.3$ using Eq. 4 for a given $\mathrm{R}_{c}$ and A, Act_ $\mathrm{VSN}_{\text {min }}$ is calculated as $\left(\lambda^{*} \mathrm{~A}\right)$ i.e.

$$
\begin{gathered}
A c t_{-} V S N_{\min }=(\lambda * A) \\
O b j_{-} F=A c t_{-} V S N=\sum^{\mathrm{T}_{-}{ }^{\mathrm{N}}{ }_{\mathrm{v}=1}\left(\text { Status }_{v}=1\right)}
\end{gathered}
$$

Status $_{v}$ is defined as follows:

Status $_{v}=\left\{1\right.$, if $\mathrm{v}^{\text {th }}$ VSN is active

0 , otherwise $\}$

The corresponding $\mathrm{E}_{\text {Tot }}$ is measured in Joule during the simulation time 0 to $\mathrm{t}$ s. It is measured using Eq. 1.

$$
\text { Per_CoV }=(\text { CoV_Randpoints } / \text { Tot_Randpoints }) * 100 \%
$$

where $\mathrm{CoV}$ Randpoints is the total number of random points covered by all VSNs in the proposed area of size A and Tot_Randpoints is the total number of random points created by the base station.

Let $\mathrm{n}_{v}$ is the number of random points covered by the FoV of $\mathrm{v}^{\text {th }} \mathrm{VSN}$ then

$$
C o V_{-} \text {Randpoints }=\bigcup_{\mathrm{v}=1}^{\mathrm{T} \_}{ }^{\mathrm{N}}\left(n_{\mathrm{v}} * \text { Status }_{\mathrm{v}}\right)
$$

\section{$5.2 \mathrm{DCC}_{1}$ :}

The BS minimizes $\left(\mathrm{Obj}_{-} \mathrm{F}\right)$. The corresponding ILP format of the proposed single-objective optimization is shown above. The BS solves this single-objective optimization problem as stated below.

Step 1: $\mathrm{DCC}_{1}$ calls a Python-based package (PuLP)[30] which calls a solver (a program), a coin-or branch cut (CBC) to solve the above single objective ILP problem for getting an optimal solution and optimal value of the objective function, (Obj_F) corresponding to the optimal solution.

Step 2: The BS stores this optimal solution as a set of values for the status of VSNs in a list, $\mathrm{L}_{o p t}$. Each value in $\mathrm{L}_{o p t}$ is either 0 (for inactive VSN) or 1 (for active VSN). $\mathrm{L}_{\text {opt }}$ stores such values for all the VSNs in the network $\left(\mathrm{T}_{-} \mathrm{N}\right)$ and hence, the size of $\mathrm{L}_{\text {opt }}\left(\mathrm{Size}_{-} \mathrm{L}_{o p t}\right)$ is $\mathrm{T}_{-} \mathrm{N}$ bits. The value for the status of $\mathrm{v}^{\text {th }} \mathrm{VSN}$ is in the $\mathrm{v}^{\text {th }}$ location of $\mathrm{L}_{o p t}$. The base station uses a counter to count the number of $1^{\prime} \mathrm{s}$ in $\mathrm{L}_{\text {opt }}$ and the count value of this counter is the optimal value of Act_VSN (Act_ VSN $\left.{ }_{\text {opt }}\right)$.

1 \begin{tabular}{lccccccccc}
\hline 1 & 1 & 1 & 0 & 0 & 1 & 1 & 0 & 0 & 1 \\
\hline 2 & 3 & 4 & 5 & 6 & 7 & 8 & 9 & 10
\end{tabular}

Fig. 1 A Snapshot of $\mathrm{L}_{\text {opt }}$ of Size 10 at the BS at the End of Step 2

For example, Fig. 1 shows $\mathrm{L}_{\text {opt }}$ for $\mathrm{T}_{-} \mathrm{N}=10$. The number of logic 1 in $\mathrm{L}_{\text {opt }}$ is 6 and hence the optimal value of the objective function $\left(\mathrm{Obj}_{-} \mathrm{F}\right)$ is 6 
i.e. Act_ $\mathrm{VSN}_{o p t}=6$. The base station computes the optimal value of $\mathrm{E}_{T o t}$

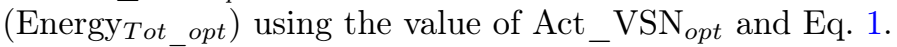

Step 3: The base station determines the identification of active VSNs using the position of logic 1 in $\mathrm{L}_{\text {opt }}$. The base station searches the base table to find the records corresponding to the identification of the active VSNs as obtained from $\mathrm{L}_{o p t}$, reads position and orientation from these records to generate FoV of these active VSNs. The base station counts the number of random points in the target area that are inside the FoV of active VSNs as $\mathrm{CoV}$ _Randpoints using Eq. 8, uses Eq. 7 to compute the value of Per_CoV using the value of Tot_Randpoints and CoV_Randpoints. Per_CoV should not be less than Init_ $\overline{\mathrm{CoV}}$ when $\mathrm{Obj}_{-} \mathrm{F}$ is equal to Act_ $\mathrm{VSN}_{\text {opt }}$. Init_CoV should also be greater than $\mathrm{Th}_{\text {coverage }}$ so that WVSN may remain functional. The base station stores Act_ VSN ${ }_{\text {opt }}$ as the optimal value of the objective functions Obj_F and Energy Tot $_{\text {opt }}$ in two separate variables.

Step 4: The BS determines the identification of inactive VSNs using the position of logic 0 in $\mathrm{L}_{o p t}$. The BS searches the BT to find the records corresponding to the identification of the inactive VSNs as obtained from $\mathrm{L}_{o p t}$, reads the position from these records and sends sleep messages to these inactive VSNs. The BS also updates these records in the BT by replacing the value of 'isVSNActive' Boolean variable from 1 to 0.

\section{$5.3 \mathrm{DCC}_{2}$ :}

$\mathrm{DCC}_{2}$ utilizes an advanced genetic algorithm (AGA)[12] based single-objective optimization technique to minimize $\mathrm{Obj}_{\text {_ }}$ s subject to connectivity constraint and coverage constraint. AGA is a special category of genetic algorithm (GA) that has characteristics like self-adaptive crossover and mutation operation, scale reproduction etc [12]. AGA adaptively varies the mutation and crossover probability following different conditions of solutions to prevent premature convergence, to preserve the solution diversity, to enhance the speed of calculation and the algorithm precision while searching for the optimum value of the objective function. In $\mathrm{DCC}_{2}$, each solution (also known as a chromosome) belonging to a population of size $\mathrm{N}_{P}$ is of length $\mathrm{T}$ N. The value for the status of $\mathrm{v}^{\text {th }}$ VSN $\left(\operatorname{Status}_{v}\right)$ is in the $\mathrm{v}^{\text {th }}$ location in the solution. All the solutions in the population are encoded in binary format as the status of each VSN is a binary variable. It is called the genetic representation of a solution. The general format of the genetic representation of a solution is shown in Fig. 2.

\begin{tabular}{lcccl}
\hline Status $_{1}$ & Status $_{2}$ & Status $_{3}$ & $\ldots$. & Status $_{T} N$ \\
\hline $1^{\text {st }} \mathrm{VSN}$ & $2^{\text {nd }} \mathrm{VSN}$ & $3^{\text {rd }} \mathrm{VSN}$ & $\mathrm{T}_{-} \mathrm{N}^{t h} \mathrm{VSN}$
\end{tabular}

Fig. 2 Genetic Representation of a Solution

DCC 2 is divided into two parts: Part 1 finds the near-optimal solution and near-optimal value of $\mathrm{Obj}_{\text {_ }} \mathrm{F}$ and Part 2 finds shutting off the maximum number of VSNs in the target area. 
Part 1: To find the near-optimal solution, Procedure GA_OPT( ) is executed.

Procedure GA_OPT $\left(\mathrm{N}_{P}, \mathrm{Gen}_{M a x}, \mathrm{p}^{\mathrm{mu}}, \mathrm{p}^{\mathrm{cr}}\right)$

Input: Initial population of size $\mathrm{N}_{P}$, number of generation $\operatorname{Gen}_{\operatorname{Max}}$, crossover and mutation probability $\mathrm{p}^{\mathrm{mu}}$ and $\mathrm{p}^{\mathrm{cr}}$ respectively.

Output: The near optimal solution after $\operatorname{Gen}_{\text {Max }}$ number of generations.

Step 1: Set the generation count $\mathrm{gc}=0$.

Step 2: Generate an initial population POP ${ }^{g c}$ containing $\mathrm{N}_{P}$ number of randomly generated solutions or chromosomes that satisfy the connectivity and coverage constraints and variable bounds.

Step 3: Compute the value of the fitness function for all the solutions in terms of Obj_F (Act_VSN).

Step 4: Apply binary tournament selection to select two better parents, then apply crossover and mutation [12] to create two offsprings of those parents.

Step 5: Do Step 4 repetitively to generate a unique offspring population (Offec) of size $\mathrm{N}_{P}$.

//replacing parent population with the offspring population

Step 6: Set $\mathrm{POP}^{\mathrm{gc}}=\mathrm{Off}^{\mathrm{gc}}$

Step 7: if $g c<\operatorname{Gen}_{M a x}$ then

set $\mathrm{gc}=\mathrm{gc}+1$;

go to Step 3;

else

Output the near-optimal solution and corresponding near-optimal value of $\mathrm{Obj}_{-} \mathrm{F}$

end

Step 8: The BS stores the near-optimal solutions in a list $\left(\mathrm{L}_{\text {opt }}\right)$. The size of $\mathrm{L}_{\text {opt }}\left(\right.$ Size__ $\left.\mathrm{L}_{\text {opt }}\right)$ is $\left(\mathrm{T}_{-} \mathrm{N}\right)$ bits. The BS stores the near-optimal value of $\mathrm{Obj}_{-} \mathrm{F}\left(\right.$ Act__ $\left.\mathrm{VSN}_{\text {opt }}\right)$ in a variable.

\footnotetext{
Part 2: Shutting off the maximum number of VSNs on the target area

The BS determines the identification of inactive VSNs using the position of logic 0 in $\mathrm{L}_{\text {opt }}$. The BS searches the BT to find the records corresponding to the identification of the inactive VSNs as obtained from $\mathrm{L}_{o p t}$, reads position from these records and sends sleep messages to these inactive VSNs. The BS also updates these records in the BT by replacing the value of the "isVSNActive' Boolean variable from 1 to 0 .
} 


\subsection{Post Duty-Cycling Scenario}

After the execution of $\mathrm{DCC}_{1} / \mathrm{DCC}_{2}$ in $\mathrm{PA}{ }_{-} 1 / \mathrm{PA} \_2$ by BS, a maximum number of VSNs slips into sleep mode in the target area. Now, the BS computes $\mathrm{T}_{-} \mathrm{N}$, number of VSNs in sleep mode (say $\left.\Gamma_{\max }\right)$ and Act_VSN $\mathrm{VPp}_{\text {opt }}\left(=\left(\mathrm{T}_{-} \mathrm{N}\right.\right.$ $\left.\left.-\bar{\Gamma}_{\max }\right)\right)$ from $\mathrm{L}_{\text {opt }}$ for the target area. The BS also calculates Per_CoV by Act_ $\mathrm{VSN}_{\text {opt }}$ in the target area from the BT. In the case of (Per_CoV $<$ $\mathrm{Th}_{\text {coverage }}$ ), the BS stops gathering data from WVSN since WVSN is no more operational now. Supposing VSN v is in active mode and (Per_CoV $\left.\geq \mathrm{Th}_{\text {coverage }}\right)$, the VSN $\mathrm{v}$ begins monitoring the target area. Owing to the continuous dissipation of energy, it will die after a certain time. Its energy having been reduced to the value, a little more than zero, the VSN v transmits and routes (utilizing GPSR) dead messages [14] to its neighbours and the BS respectively. The size of the dead message (Size_D) being 17 bits)[14], the BS searches the BT by the id of the VSN after receiving the dead message from the VSN v, updating the values, isVSNActive[14] and isVSNDead[14] to 0 and 1 respectively for it. $\mathrm{VSN}_{1}$, (a neighbour VSN of the VSN v say) becomes active when it receives a dead message from the VSN v. These phenomena will happen for all dead VSNs and consequently, the sleeping VSNs belonging to $\Gamma_{\max }$ become active. The BS now searches for records of sleeping VSNs (belonging to the set $\Gamma_{\max }$ ) in the BT with the observation of values of isVSNActive and isVSNDead set as 0 and 0 respectively. VSNs being active now, the BS updates the values of isVSNActive and isVSNDead to 1 and 0 respectively.

All the sleeping VSNs $\left(\in \Gamma_{\max }\right)$ being active, the BS again calculates Per_CoV by $\Gamma_{\max }\left(=\left(\mathrm{T}_{-} \mathrm{N}\right.\right.$-Act_VSN $\left.\left.\mathrm{VSp}_{\text {opt }}\right)\right)$ number of VSNs. The BS will stop collecting data from WVSN at this point if Per_CoV is less than $\mathrm{Th}_{\text {coverage }}$. Otherwise, Act_VSN $\left(\in \Gamma_{\max }\right)$ will go on monitoring the target area till they die owing to energy deficiency.

\section{Qualitative Performance}

The evaluation of the qualitative performance is carried out with respect to communication overhead ( $\mathrm{CM}$ _OV), computation overhead (CP_OV) and storage overhead (ST_OV) for the two schemes (PA_1 and PA_2). The existing approach, ET_3 corresponds to EX_3 of [14]. The CM_OV, CP_OV and ST OV of APP $\overline{5}$, APP 6 and ET 3 are already evaluated in [14] $\overline{\text { and have }}$ been shown in Table 2 and Table 3 . In the worst-case, each VSN in the target area for PA_1, PA_2 has $\left(\mathrm{T}_{-} \mathrm{N}-1\right)$ number of neighbour VSNs. The overheads are studied in the worst case in the target area.

CM OV: CM OV of the two schemes is elaborated in this section. It is the summation of the communication overhead in the neighbour discovery phase $\left(\mathrm{CM}_{-} \mathrm{OV}_{1}\right)$, registration phase $\left(\mathrm{CM}_{-} \mathrm{OV}_{2}\right)$ and duty cycling phase $\left(\mathrm{CM}_{-} \mathrm{OV}_{3}\right)$ for $\mathrm{PA}{ }_{-} 1$ and $\mathrm{PA} \_$.

CM_OV $\mathrm{OV}_{1}$ : In $\mathrm{PA}_{-} 1$ and $\mathrm{PA} 2$ each VSN sends a packet of size Size_Rec_NT bits [1 $\overline{4}]$ to its $\left(\mathrm{T}_{-}{ }_{-} \mathrm{N}-1\right)$ number of neighbours. Therefore, $\mathrm{CM}_{-} \mathrm{OV}_{1}$ in $\mathrm{PA}{ }_{-}$, $\mathrm{PA}_{-} 2$ is (Size $\mathrm{Rec}_{-} \mathrm{NT}^{*} \mathrm{~T}_{-} \mathrm{N}^{*}\left(\mathrm{~T}_{-} \mathrm{N}-1\right)$ ) bits 
CM_OV $\mathrm{OV}_{2}$ : In PA_1, PA_2 each VSN routes a packet of size Size_Rec_NT bits [14] to the BS. So CM_OV ${ }_{2}$ in $\mathrm{PA}_{-} 1, \mathrm{PA}_{-} 2$ is (Size $\mathrm{Rec}_{-} \mathrm{NT}^{*} \mathrm{~T}_{-} \mathrm{N}$ ) bits

CM_OV 3 : In PA_1 and PA_2 the BS routes sleep message of size Size_id bits to $\left(\mathrm{T}_{-} \mathrm{N}\right.$-Act_ $\left.\overline{\mathrm{VSN}}_{\min }\right)$ number of VSNs. A dead message of size Size_D is sent by each VSN to its $\left(\mathrm{T}_{-} \mathrm{N}-1\right)$ number of neighbours and to the BS respectively in $\mathrm{PA} \_$1, PA_2. Hence, $\mathrm{CM}_{-} \mathrm{OV}_{3}$ is $\left(\mathrm{Size} \_\mathrm{id}\right) *\left(\mathrm{~T} \_\mathrm{N}-\right.$ Act_ $\left.\mathrm{VSN}_{\text {min }}\right)$ $+\left(\text { Size } \_ \text {D }\right)^{*} \mathrm{~T}_{-} \mathrm{N}^{*}\left(\overline{\mathrm{T}} \_\mathrm{N}-1\right)+\left(\mathrm{Size}_{-} \overline{\mathrm{D}}^{*}\left(\mathrm{~T}_{-} \mathrm{N}\right)\right.$ bits for $\mathrm{PA} \overline{-}_{-} 1$ and $\overline{\mathrm{PA}}{ }_{-} 2$

$\mathrm{ST}_{-} \mathrm{OV}: \mathrm{ST} \_\mathrm{OV}$ of the three schemes is elaborated $\overline{\mathrm{in}}$ this section. It is the summation of the storage overhead in the neighbour discovery phase $\left(\mathrm{ST}_{-} \mathrm{OV}_{1}\right)$, registration phase $\left(\mathrm{ST}_{-} \mathrm{OV}_{2}\right)$ and duty cycling phase $\left(\mathrm{ST}_{-} \mathrm{OV}_{3}\right)$ for $\mathrm{PA}_{-} 1$ and $\mathrm{PA} \_$.

$\mathrm{ST}_{-} \mathrm{OV}_{1}$ : Each VSN stores $\mathrm{T}_{-} \mathrm{N}$ number of records each of size Size_Rec_NT bits [14] in $\mathrm{PA}_{-} 1$ and $\mathrm{PA} \_$2. So $\mathrm{ST}_{-} \mathrm{OV}_{1}$ in $\mathrm{PA}{ }_{-}$, $\mathrm{PA} \_2$ is (Size Rec NT*T N*T N) bits.

$\mathrm{ST} \overline{\mathrm{OV}}_{2}$ : In $\overline{\mathrm{PA}}_{-} 1$ and $\mathrm{PA} \_2$, the $\mathrm{BS}$ stores $\mathrm{T}_{-} \mathrm{N}$ number of records in the BT. Each record has (Tot_Param +2 ) number of parameters [14] of size (Size Rec $\mathrm{NT}+2$ ) bits [14]. So, ST $\mathrm{OV}_{2}$ in PA 1, PA 2 is $(\text { Size_Rec_NT̄ }+2)^{*}{ }^{*}{ }_{-} \mathrm{N}$ bits.

$\mathrm{ST}_{-} \mathrm{OV}_{3}$ : The BS stores the optimal solution in $\mathrm{L}_{o p t}$ after the execution of $\mathrm{DCC}_{1}$ in $\mathrm{PA} \overline{ }_{-}$and $\mathrm{DCC}_{2}$ in $\mathrm{PA}{ }_{-}$. Size of $\mathrm{L}_{\text {opt }}$ i.e. Size_L $\mathrm{L}_{\text {opt }}$ is $\mathrm{T}_{-} \mathrm{N}$

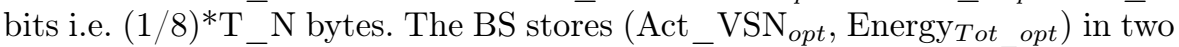
separate variables both in PA 1 and PA 2. The data type of the variable which holds the value of Act $\mathrm{V}_{\bar{S}} \mathrm{~N}_{o p t}$ is int. The data type of the variable which holds the value of Energy Tot_opt $_{\text {is }}$ float. Therefore, the total size needed to hold Act_VSN $\mathrm{Vpt}_{\text {opt }}$ and Energy $\mathrm{y}_{\text {Tot opt }}$ is $(2+4)$ bytes i.e. 6 bytes. So, ST_OV 3 both in $\overline{\mathrm{PA}} \_1$ and $\mathrm{PA} \_2$ is $\left((1 / \overline{8}) * \mathrm{~T}_{-} \mathrm{N}+6\right)$ bytes.

$\mathrm{CP} \mathrm{OV}$ : $\mathrm{CP} \mathrm{OV}$ of the three schemes is elaborated in this section. It is the summation of the computation overhead in the neighbour discovery phase $\left(\mathrm{CP} \_\mathrm{OV}_{1}\right)$, registration phase $\left(\mathrm{CP}_{-} \mathrm{OV}_{2}\right)$ and duty cycling phase $\left(\mathrm{CP} \_\mathrm{OV}_{3}\right)$ for PA_ 1 and PA_2.

$\mathrm{CP}_{-}^{-} \mathrm{OV}_{1}$ : Each VSN inserts $\mathrm{T}_{-} \mathrm{N}$ number of records in its neighbour table in the two schemes. In $\mathrm{PA}-1$ and $\mathrm{PA} 2$, each record consists of Tot_Param [14] number of parameters. So, $\mathrm{CP}_{-} \mathrm{OV}_{1}$ in $\mathrm{PA}{ }_{-}$, $\mathrm{PA}_{-} 2$ is $\mathrm{O}\left(\overline{\mathrm{Tot}} \_\right.$Param*T_N$)$i.e. $\mathrm{O}\left(\mathrm{T}_{-} \mathrm{N}\right)$

$\mathrm{CP}_{-}^{-} \mathrm{OV}_{2}$ : The BS inserts $\mathrm{T}_{-}^{-} \mathrm{N}$ number of records in the BT in $\mathrm{PA}_{-} 1$ and PA 2. Each record in the BT contains (Tot Param +2$)$ number of parameters. So, $\mathrm{CP}_{-} \mathrm{OV}_{2}$ in $\mathrm{PA} \_1, \mathrm{PA} \_2$ is $\left.\mathrm{O}\left(\left(\text { Tot_}{ }_{-} \text {aram }+2\right)^{*} \mathrm{~T}_{-} \mathrm{N}\right)\right)$ i.e. $\mathrm{O}\left(\mathrm{T}_{-} \mathrm{N}\right)$

$\mathrm{CP} \mathrm{OV}_{3}$ : The computation overhead of $\mathrm{PA}_{-} 1$ in the duty cycling phase is due to the computation overhead of $\mathrm{DCC}_{1}$ executed by the base station. $\mathrm{DCC}_{1}$ employs ILP based optimization technique. In this phase, $2^{T}{ }_{-}^{N}$ number of possible values to the decision variables $\left(\right.$ Status $_{1}$, Status $_{2}, \ldots \ldots$ Status $_{T}{ }_{N}$ ) is assigned in a non-deterministic manner. The computation overhead to check the feasibility of each solution is $\mathrm{O}\left(\mathrm{T}_{-} \mathrm{N}\right)$ and to evaluate the value of the objective function for each solution is $\overline{\mathrm{O}}(\mathrm{T}+\mathrm{N})$. 
The computation overhead of $\mathrm{PA}_{-} 2$ in the duty cycling phase is due to the computation overhead of $\mathrm{DCC}_{2}$ executed by the base station. The computation overhead of AGA utilized by $\mathrm{DCC}_{2}$ is $\mathrm{O}$ (population size * length of each chromosome ${ }^{*}$ number of generations) i.e. $\mathrm{O}\left(\mathrm{N}_{P} * \mathrm{~T}_{-} \mathrm{N} * \operatorname{Gen}_{M A X}\right)$. The BS stores the near-optimal solution in $\mathrm{L}_{o p t}$ with computation overhead is $\mathrm{O}(1)$. The BS computes (Act_ $\mathrm{VSN}_{\text {opt }}$ and Energy $\mathrm{T}_{\text {Tot }}$ opt ) corresponding to the near-optimal solution in $\mathrm{L}_{o p t}$ and inserts them in two separate variables with computation overhead $\mathrm{O}\left(\mathrm{T}_{-} \mathrm{N}\right)$.

So, $\mathrm{CP}_{-} \mathrm{OV}_{3}$ in

- $\mathrm{PA}_{-} \overline{1}$ is $2^{T}{ }^{N} \mathrm{x}\left\{\mathrm{O}\left(\mathrm{T}_{-} \mathrm{N}\right)+\mathrm{O}\left(\mathrm{T}_{-} \mathrm{N}\right)\right\}$ i.e. $\mathrm{O}\left(2^{T}{ }_{-}{ }^{N} * \mathrm{~T}_{-} \mathrm{N}\right)$ i.e. exponential

- $\mathrm{PA} \_2$ is $\mathrm{O}\left(\mathrm{N}_{P} * \mathrm{~T}_{-} \mathrm{N} * \mathrm{Gen}_{M A X}\right)+\mathrm{O}(1)+\mathrm{O}\left(\mathrm{T}_{-} \mathrm{N}\right)$ i.e. $\mathrm{O}\left(\mathrm{N}_{P} * \mathrm{~T}_{-} \mathrm{N}\right.$ $\left.* \operatorname{Gen}_{M A X}\right)+\mathrm{O}\left(\mathrm{T}_{-} \mathrm{N}\right)$

Therefore, $\mathrm{CP}$ OV in

- $\mathrm{PA} \_1$ is $\mathrm{O}\left(\overline{\mathrm{T}}_{-} \mathrm{N}\right)+\mathrm{O}\left(\mathrm{T}_{-} \mathrm{N}\right)+\mathrm{O}\left(2^{T}{ }_{-}{ }^{N} * \mathrm{~T}_{-} \mathrm{N}\right)$ i.e. $\mathrm{O}\left(\mathrm{T}_{-} \mathrm{N}_{x} 2^{T}{ }_{-}{ }^{N}\right)$

- $\mathrm{PA}_{-} 2$ is $\mathrm{O}\left(\mathrm{T}_{-}^{-} \mathrm{N}\right)+\mathrm{O}\left(\mathrm{T}_{-}^{-} \mathrm{N}\right)+\mathrm{O}\left(\mathrm{N}_{P} * \mathrm{~T}_{-} \overline{\mathrm{N}}^{-} \operatorname{Gen}_{M A X}\right)+\mathrm{O}\left(\mathrm{T}_{-} \mathrm{N}\right)$ i.e. $\mathrm{O}\left(\mathrm{T}_{-} \mathrm{N}\right)+\mathrm{O}\left(\mathrm{N}_{P} * \mathrm{~T}_{-} \mathrm{N} * \mathrm{Gen}_{M A X}\right)$

- $\mathrm{APP}_{-} 5[14]$ and $\mathrm{APP}_{-} 6[14]$ is $\mathrm{O}\left(\mathrm{T}_{-} \mathrm{N}^{6}\right)[14]$

- $\mathrm{ET}_{-} 3$ is $\mathrm{O}\left(\mathrm{T}_{-} \mathrm{N}^{2}\right)[14]$

$\mathrm{CP} \_\overline{\mathrm{OV}}$ is highest in $\mathrm{PA}_{-} 1$ (exponential) and lowest in $\mathrm{ET} \_3$. CP_OV of $\mathrm{APP}_{-} 5$ and $\mathrm{APP}_{-} 6$ are the same. $\mathrm{CP}_{-} \mathrm{OV}$ of $\mathrm{ET}_{-} 3$ is lesser than that of $\mathrm{APP}_{-} 5, \mathrm{APP}_{-} 6 . \mathrm{CP}_{-} \mathrm{OV}$ of $\mathrm{PA}_{-} 2$ cannot be compared with $\mathrm{PA}_{-} 1$, $\mathrm{APP}_{-} 5, \mathrm{APP}_{-} 6$ and $\mathrm{ET} \_3$ as $\mathrm{CP}_{-} \mathrm{OV}$ of $\mathrm{PA} \_2$ depends on two other variables, $\operatorname{Gen}_{M A X}$ and $\mathrm{N}_{P}$ apart from $\mathrm{T}_{-} \mathrm{N}$ unlike $\mathrm{CP}_{-} \mathrm{OV}$ of the rest of the approaches.

CM_OV and ST_OV for the five schemes are calculated and shown in Table 2 and Table 3 respectively when $\mathrm{T}_{-} \mathrm{N}_{\text {is }} 70$ and 100.

Table 2 Comparative Study of CM_OV and ST_OV Among PA_1, PA_2, APP_5, APP_6 and ET_3 for $\mathrm{T} \_\mathrm{N}=70$

\begin{tabular}{lll}
\hline & CM_OV & ST_OV \\
\hline PA_1 & 230.36 kilobytes & 0.21 megabytes \\
PA_2 & 230.36 kilobytes & 0.21 megabytes \\
APP_5[14] & 231.33 kilobytes & 64.35 megabytes \\
APP_6[14] & 231.33 kilobytes & 64.35 megabytes \\
ET_3[14] & 241.54 kilobytes & 0.22 megabytes \\
\hline
\end{tabular}

Table 3 Comparative Study of CM_OV and ST_OV Among PA_1, PA_2, APP_5, APP_6 and ET_3 for $\mathrm{T}_{-} \mathrm{N}=100$

\begin{tabular}{|c|c|c|}
\hline & CM & OV \\
\hline PA 1 & $470 . \overline{11}$ kilobytes & 0.44 megabytes \\
\hline $\mathrm{PA}^{-} 2$ & 470.11 kilobytes & 0.44 megabytes \\
\hline $\mathrm{APP} \_5[14]$ & 471.62 kilobytes & 92.05 megabytes \\
\hline $\mathrm{APP}^{-} 6[14]$ & 471.62 kilobytes & 92.05 megabytes \\
\hline ET_3[14] & 492.58 kilobytes & 0.45 megabytes \\
\hline
\end{tabular}


It is observed from Table 2 and Table 3 that CM_OV is the least and the same for $\mathrm{PA}_{-} 1$ and $\mathrm{PA} \_$2. CM_OV is highest in ET_3. CM_OV is less in $\mathrm{APP}_{-} 5$ and $\mathrm{APP}_{-} 6$ than in ET_3. It is also observed from Table 2 and Table 3 that $\mathrm{ST}_{-} \mathrm{OV}$ is least in $\mathrm{PA}_{-} 1$ and $\mathrm{PA}_{-} 2$, highest in $\mathrm{APP}_{-} 5$ and $\mathrm{APP} \_6$, less in $\mathrm{ET}_{-} 3$ than in $\mathrm{APP}_{-} 5$ and $\mathrm{APP}_{\overline{6}}$.

\section{Quantitative Performance}

With the use of the OMNET ++ Castalia simulator [31], both PA_1 and PA_2 are simulated. WVSN-v4 framework [32] which supports the modelling of video sensor coverage contains a simulation model of WVSN. A particular VSN possessing a larger processing capability is supposed as the BS both in PA_1 and PA_2. The BS utilizes pulp [30] and pymoo [33] (both are python based packages) to get an optimal solution and a near-optimal solution respectively in the duty-cycling phase. Pymoo is a python based package for solving the problem of optimization utilizing different stochastic methods like Genetic Algorithm, Non-Dominated Sorting Genetic Algorithm-II (NSGA-II), PSO etc. The summarization of the basic simulation environment, a simulation environment for energy consumption, tunable MAC parameters and GPSR protocol parameters have been substantiated in TABLE 5, TABLE 6, TABLE 7 and TABLE 8 in [14] respectively for PA_1 and PA_2. Table 4 summarizes parameters used in $\mathrm{DCC}_{2}$. Fig. 12 in [14] shows the layout of VSN taken over in the present work.

Table 4 Parameters Used in $\mathrm{DCC}_{2}$

\begin{tabular}{ll}
\hline Parameter & Value \\
\hline Population size $\left(\mathrm{N}_{P}\right)$ & 100 \\
Offspring population size & 100 \\
Crossover probability $\left(\mathrm{P}^{c r}\right)$ & variable \\
Mutation probability $\left(\mathrm{P}^{m u}\right)$ & variable \\
Crossover Operator & Two point \\
Mutation Operator & Bitflip \\
Number of Generations $\left(\mathrm{Gen}_{M a x}\right)$ & 50 \\
\hline
\end{tabular}

\subsection{Simulation Metric}

The quantitative performance of $\mathrm{PA}_{-} 1$ and $\mathrm{PA}_{-} 2$ is studied based on Act_VSN, $\mathrm{E}_{\text {Tot }}$ (in Joule), residual energy ( $\mathrm{E}_{\text {Res }}$ ) (in Joule), Per_CoV (in percentage) and network lifetime (in seconds) in the target area.

Act_VSN should be as small as possible to reduce $\mathrm{E}_{T o t}$ and to increase the network lifetime (defined in [14]). Eq. 6 measures Act_VSN.

$\mathrm{E}_{\text {Tot }}$ which is measured using Eq. 1 should be as small as possible for enhancing the network lifetime.

Residual energy $\left(\mathrm{E}_{\text {Res }}\right)$ should be as large as possible to enhance the network lifetime. It is computed as (Total Initial Energy of VSNs - $\mathrm{E}_{T o t}$ ). 
Per_CoV should be at the closest level of the coverage area when all VSNs in the target area are in active mode. Eq. 7 measures Per_CoV.

The objective of the proposed approaches ( $\left.\mathrm{PA}_{-} 1, \mathrm{PA}_{-} 2\right)$ is to minimize Act_VSN and $\mathrm{E}_{\text {Tot }}$ and to maximize $\mathrm{E}_{\text {Res }}$ and network lifetime without losing Per_CoV. Therefore, Act_VSN, $\mathrm{E}_{\text {Tot }}, \mathrm{E}_{\text {Res }}$, Per_CoV and network lifetime constitute the five simulation metrics.

With the increase in the total number of deployed VSNs in the target area (node density) Act_VSN increases and as a result of which $\mathrm{E}_{\text {Tot }}$, Per_CoV, $\mathrm{E}_{\text {Res }}$ and network lifetime also increase. Therefore, the variation of Act_ VSN, $\mathrm{E}_{\text {Tot }}, \mathrm{E}_{\text {Res }}$, Per_CoV and network lifetime is studied with the variation of the node density during simulation. The increase in the total number of function evaluations (Function Evaluation) defined as the product of population size and the number of generations in GA_OPT decreases Act_VSN if GA_OPT converges to the optimum value of Act_VSN i.e. Act_ $\mathrm{VSN}_{\text {opt }}$. Therefore, the variation of Act_VSN is examined by varying Function Evaluation during simulation.

\subsection{Simulation Results and Performance Evaluation}

Five simulation experiments are conducted to compare the performance of $\mathrm{PA}_{-} 1$ and $\mathrm{PA}_{-} 2$ with $\mathrm{APP}_{-} 5, \mathrm{APP}_{-} 6, \mathrm{ET}_{-} 3$ and Init_Ran. The sixth simulation experiment is also conducted during the simulation of $\mathrm{PA}_{-} 2$ for studying the convergence of GA_OPT to the optimum value of Act_VSN i.e. Act_ $\mathrm{VSN}_{\text {opt }}$. All the simulation experiments except the fifth simulation experiment have been conducted for the duration (0-700) s. The fifth simulation experiment is conducted for (0-1500) s.

\subsubsection{Act VSN versus Node Density}

The first simulation experiment is conducted for observing the variation of Act_VSN with node density. The plot of Act_VSN vs. node density for Init_Ran, PA_1, PA_2, APP_5, APP_6 and ET_3 is shown in Fig. 3.

Act_VSN increases with node density for all the six schemes (Init_Ran, $\left.\mathrm{PA}_{-} 1, \overline{\mathrm{PA}} \_2, \mathrm{APP}_{-} 5, \mathrm{APP}_{-} 6, \mathrm{ET}_{-} 3\right)$, which is quite obvious, as observed from Fig. 3. Act_VSN is highest for Init_Ran and least for PA_1, less in $\mathrm{PA}_{-} 2$ than in $\mathrm{APP} \overline{P P}_{-}, \mathrm{APP}_{-} 6$ and $\mathrm{ET} \_\overline{3}$, less in $\mathrm{APP} \_6$ than in $\mathrm{APP}_{-} 5$, $\mathrm{ET} \_3$, less in $\mathrm{APP}_{-} 5$ than in $\mathrm{ET}_{-} 3$ (for node density $>100$ ).

\subsection{2 $\mathrm{E}_{\text {Tot }}$ versus Node Density}

The second simulation experiment is conducted for observing the variation of $\mathrm{E}_{\text {Tot }}$ with node density. The plot of $\mathrm{E}_{\text {Tot }}$ vs. node density for Init_Ran, PA_1, $\mathrm{PA} \_$, $\mathrm{APP}_{-} 5, \mathrm{APP}_{-} 6$ and $\mathrm{ET}_{-} 3$ is shown in Fig. 4.

$\overline{\mathrm{E}}_{\text {Tot }}$ increases with node density for all the six schemes (Init_Ran, PA_1, PA_2, APP_5, APP_6, ET_3) as observed from Fig. 4. E $\mathrm{E}_{\text {Tot }}$ is the largest for Init_Ran and minimum for $\mathrm{PA}_{-}$, less in $\mathrm{PA} \_2$ than in $\mathrm{APP} \_5, \mathrm{APP} \_6$ 


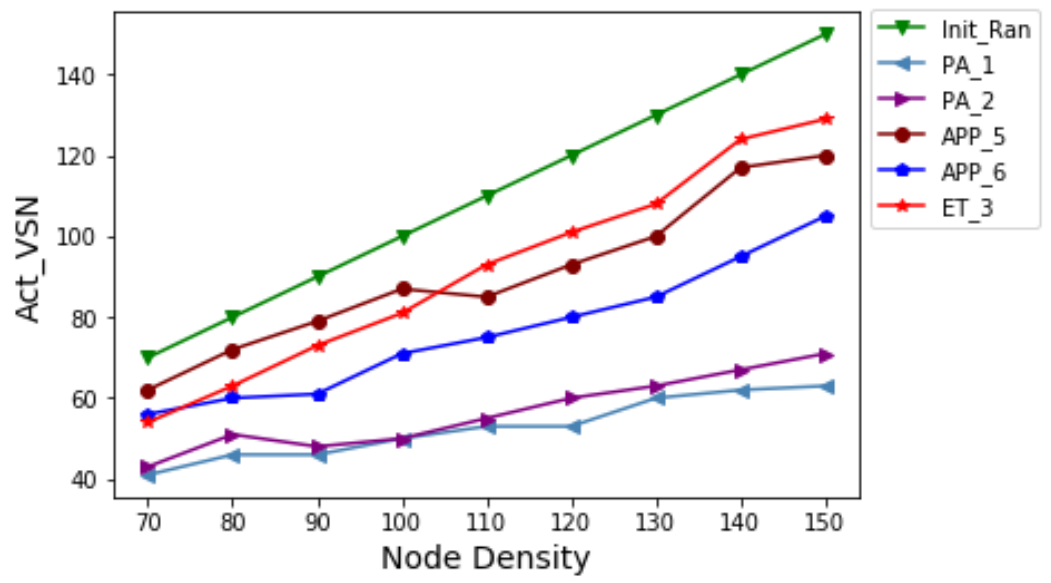

Fig. 3 Act_VSN vs Node Density

and $\mathrm{ET}_{-} 3$, less in $\mathrm{APP}_{-} 6$ than in $\mathrm{APP}_{-} 5, \mathrm{ET}_{-} 3$, less in $\mathrm{APP}_{-} 5$ than in ET_3 (for node density $>100)$.

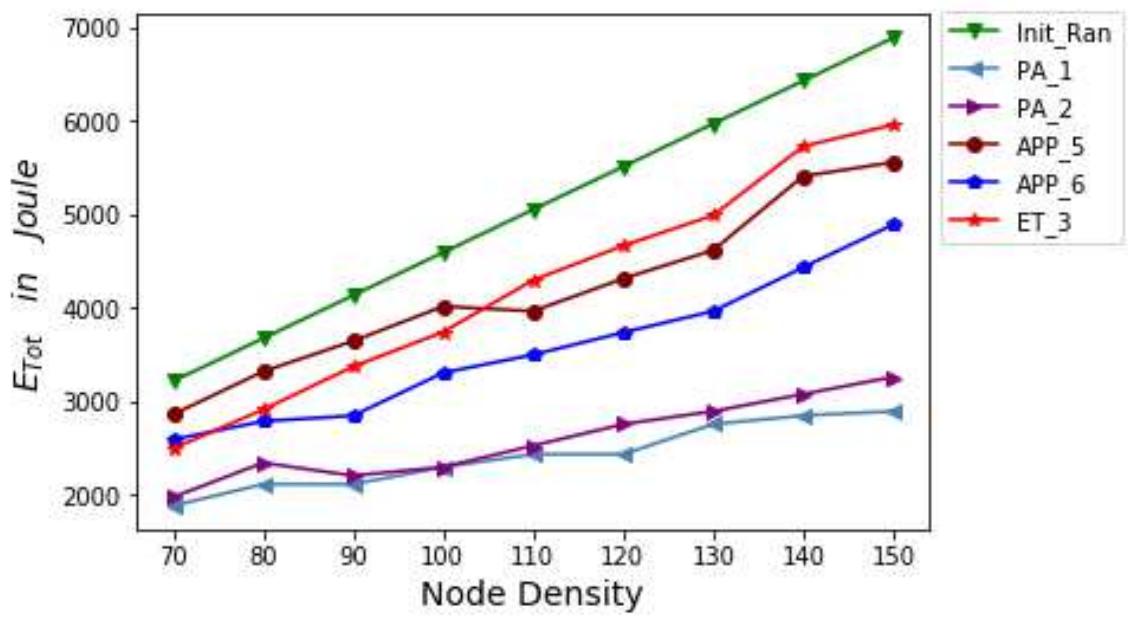

Fig. $4 \mathrm{E}_{\text {Tot }}$ vs Node Density

\subsection{3 $\mathrm{E}_{\text {Res }}$ versus Node Density}

The third simulation experiment is conducted for observing the variation of $\mathrm{E}_{\text {Res }}$ with node density. The plot of $\mathrm{E}_{\text {Res }}$ vs. node density for Init_Ran, PA_1, PA_2, APP_5, APP_6, and ET_3 is shown in Fig. 5.

$\overline{\mathrm{E}}_{\text {Res }}$ increases with node density for all the six schemes (Init_Ran, PA_1, PA_2, APP_5, APP_6, ET_3) as observed from Fig. 5. $\mathrm{E}_{\text {Res }}$ is least for 
Init_Ran and the largest for $\mathrm{PA} \_$, greater in $\mathrm{PA} \_2$ than in $\mathrm{APP}$ 5, APP 6 and $\mathrm{ET}_{-} 3$, greater in $\mathrm{APP}_{-} 6$ than in $\mathrm{APP}_{-} 5, \mathrm{ET}_{-} 3$, greater in $\mathrm{APP}_{-} 5$ than in $\mathrm{ET}_{-} \overline{3}$ (for node density $>100$ ).

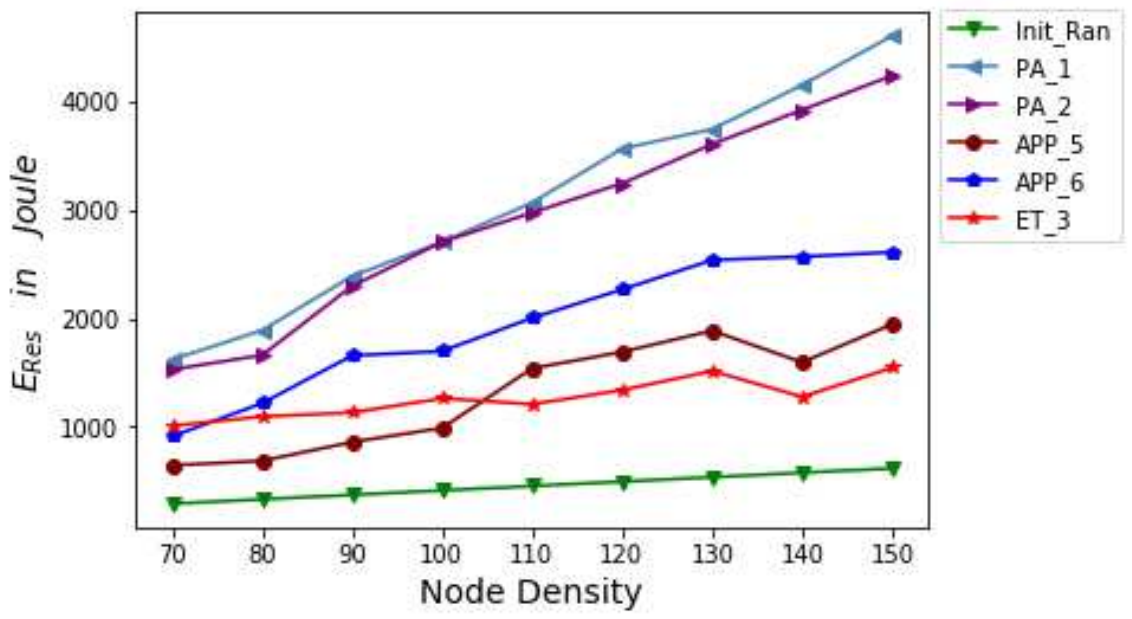

Fig. $5 \mathrm{E}_{\text {Res }}$ vs Node Density

\subsubsection{Per_CoV versus Node Density}

The fourth simulation experiment is conducted for observing the variation of Per_CoV with node density. The plot of Per_CoV vs. node density for Init_Ran, $\mathrm{PA}_{-}$1, $\mathrm{PA}_{-} 2, \mathrm{APP}_{-} 5, \mathrm{APP}_{-} 6$ and ET_3 is shown in Fig. 6.

$\bar{P}$ er_CoV increases with node density for all the six schemes (Init_Ran, $\mathrm{PA}_{-}$1, $\overline{\mathrm{PA}}_{-}$2, $\mathrm{APP}_{-}$5, APP $\_$6, ET_3) as observed from Fig. 6. Per_ $\overline{\mathrm{COV}}$ is the largest for Init_ $\bar{R}$ an, $\mathrm{PA}_{-} 1, \mathrm{PA}_{-} 2$ and lowest for $\mathrm{APP}{ }_{-} 6$, less in $\mathrm{APP}_{-} 5$ than $\mathrm{ET}_{-} 3$ (for node density $\left.>100\right)$.

\subsubsection{Network Lifetime versus Node Density}

The fifth simulation experiment is conducted for observing the variation of network lifetime with node density. The plot of network lifetime vs. node density for Init_Ran, $\mathrm{PA}_{-}$, $\mathrm{PA}_{-} 2, \mathrm{APP}_{-} 5, \mathrm{APP}_{-} 6$ and $\mathrm{ET} \_3$ is shown in Fig. 7.

It is observed from Fig. 7 that network lifetime is least in Init_Ran and ET_3 (770 s) and highest in PA_1 and PA_2 (1500 s) for all node density. It lesser in $\mathrm{APP}_{-} 6$ than in $\mathrm{PA}_{-} 1$ and $\mathrm{PA}_{-} 2$ for the node density less than equal to 80 . It is lesser in $\mathrm{APP}_{-}{ }^{-} 5$ than in $\mathrm{PA}_{-} 1, \mathrm{PA}_{-} 2$ and $\mathrm{APP}_{-} 6$ for all node densities except node density 120 and 150 . 


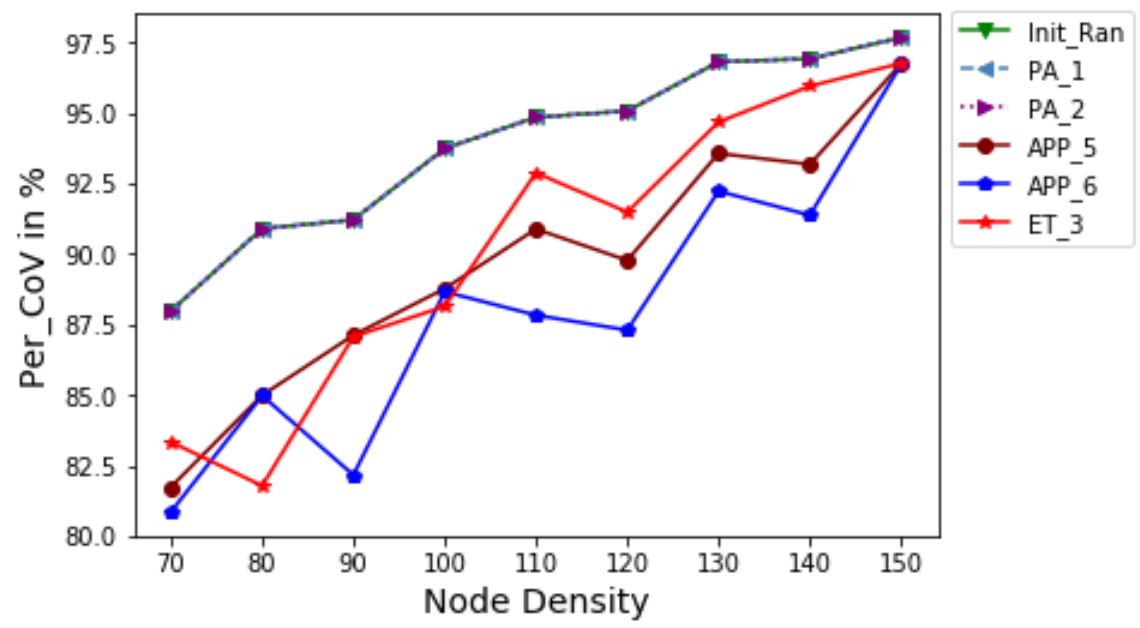

Fig. 6 Per_CoV vs Node Density

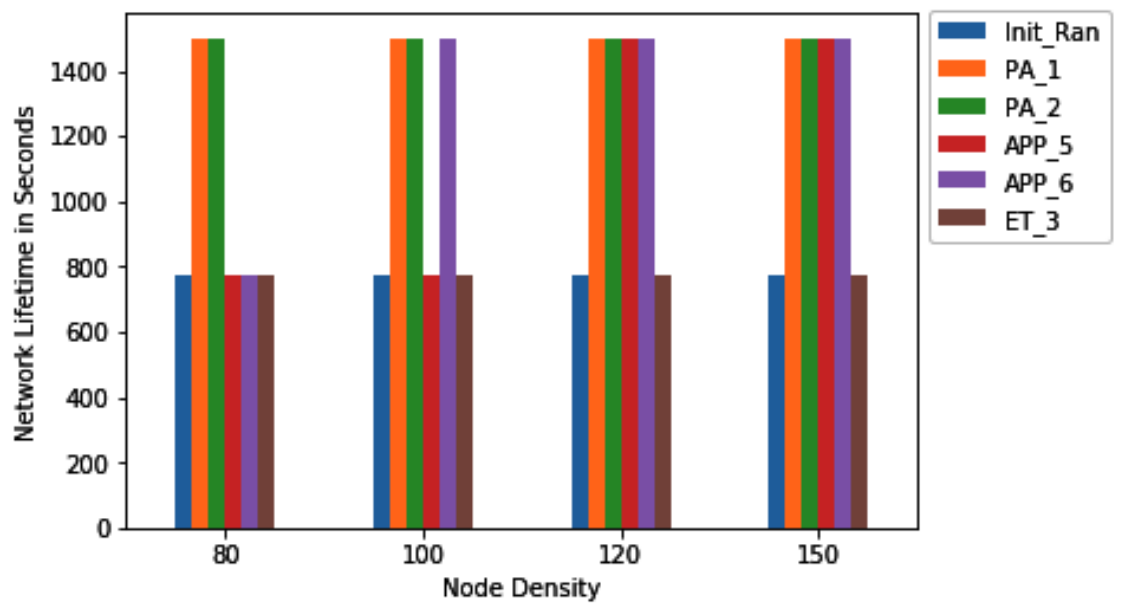

Fig. 7 Network Lifetime vs Node Density

\subsubsection{Act_VSN versus Function Evaluation}

The sixth simulation experiment is conducted for observing the variation of Act_VSN with Function Evaluation in PA_2. The plot of Act_VSN versus Function Evaluation for PA_2 is shown in Fig. 8 and Fig. 9 when node density equals 70 and 80 respectively. Act_VSN decreases with Function Evaluation as observed from Fig. 8 and Fig. $\overline{9}$ It is also observed from Fig. 8 and Fig. 9 that Act_VSN becomes almost parallel to the Function Evaluation axis when Function Evaluation is greater than 1500 and 4500 respectively. It means Act_VSN has already reached its optimal value $\left(\right.$ Act_VSN $\left.\mathrm{VPt}_{\text {opt }}\right)$ at Function 
Evaluation greater than 1500 (or $\operatorname{Gen}_{M a x}>15$ ) and greater than 4500 (or $\operatorname{Gen}_{\operatorname{Max}}>45$ ) for Fig. 8 and Fig. 9 respectively.

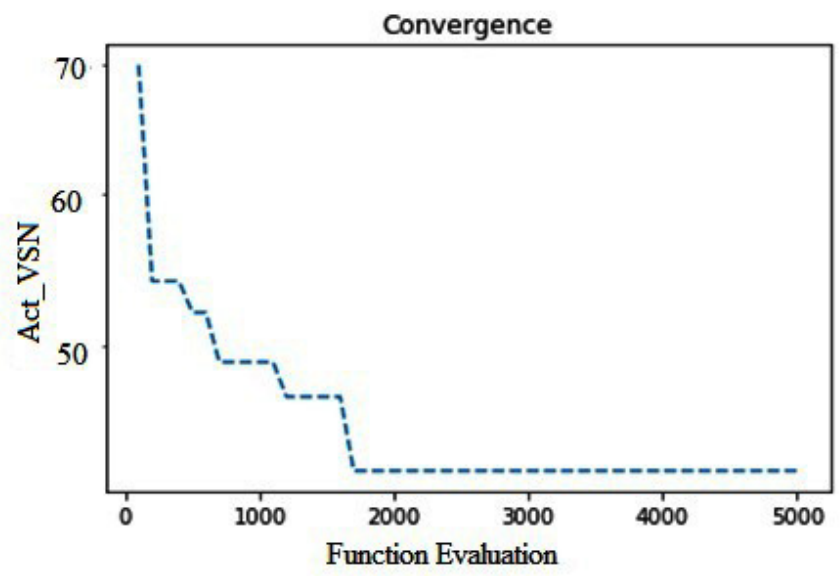

Fig. 8 Act_VSN vs Function Evaluation (Node Density=70) for PA_2

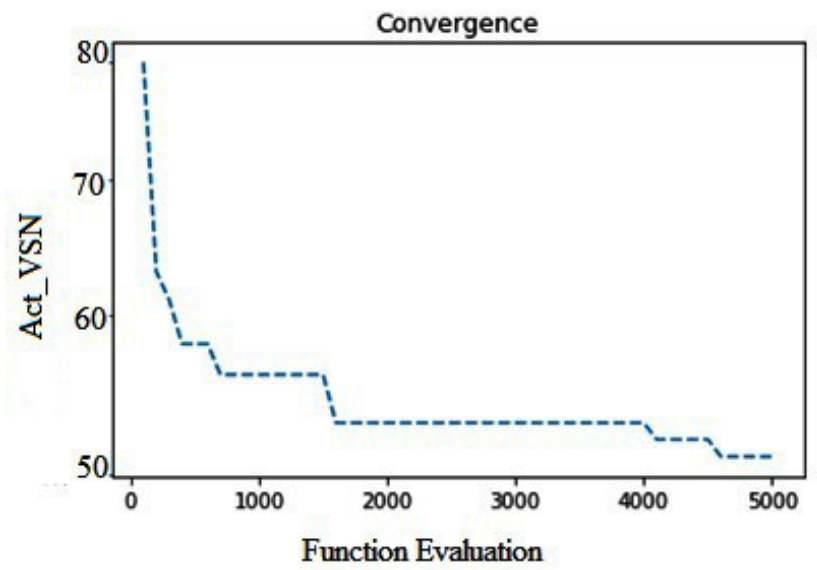

Fig. 9 Act_VSN vs Function Evaluation (Node Density=80) for PA_2

\section{Performance of $\mathrm{PA}_{-} 1$ and $\mathrm{PA}_{-}$2: Observation}

It is observed that APP_6 produces a better result than that of (APP_5, APP_6 and ET_3) with regard to $\mathrm{E}_{T o t}$. ET_3 shows the best results among 
these three state-of-the-art works with regard to Per_CoV. Act_VSN is lesser in $\mathrm{PA}_{-} 1$ compared to $\mathrm{PA} \_$2. $\mathrm{PA}{ }_{-} 1$ and $\mathrm{PA}_{-} 2$ are able to reduce $\mathrm{E}_{T o t}$ by $40.85 \%$ and $33.34 \%$ respectively from the existing best approach APP 6 (with respect to $\mathrm{E}_{\text {Tot }}$ ) for 150 deployed VSNs over the target area. With the reduction in Act_VSN, $\mathrm{E}_{\text {Tot }}$ also decreases but at the expense of reduced Per_CoV in $\mathrm{APP}_{-} 5,{ }_{-} \mathrm{APP} \_6$ and $\mathrm{ET} \_3$. But the reduction in Act_VSN doesn't cause a reduction in Per_ $\overline{C o V}_{-}$in $\overline{\mathrm{PA}} \_1$ and $\mathrm{PA} \_2$. For the same node density, both PA_1 and PA_2 gain a little amount of Per_CoV (i.e. 0.94\%) than the existing $\bar{b}$ etter approach ET_3 (in terms of Per_CoV). Both PA_1 and PA_2 have the same CM_OV. Both of them show better results by $0 . \overline{3} 2 \% /(4.25 \% \overline{\%})$ from $\left(\mathrm{APP} \_5 \& \mathrm{APP}{ }_{-}\right) /\left(\mathrm{ET} \_3\right)$ in terms of $\mathrm{CM} \_\mathrm{OV}$ for 100 deployed VSNs on the same target area. Finally, PA_1 reveals its superiority concerning reduced $\mathrm{E}_{\text {Tot }}(11.26 \%)$ than that of PA_${ }_{-}^{2}$ without losing Per_CoV for 150 deployed VSNs.

\section{Experimental Analysis}

In all the approaches $\mathrm{PA}_{-} 1, \mathrm{PA}_{-} 2 /\left(\mathrm{APP}_{-} 5, \mathrm{APP}_{-} 6, \mathrm{ET}_{-} 3\right)$ each VSN executes the neighbour discovery phase, registration phase and duty-cycling phase/(scheduling phase) sequentially. In the scheduling phase of (APP_5, APP_6), each VSN has to undergo two sub-phases - backup set computation and duty cycling [14]. Each VSN has to undergo two sub-phases- redundancy judgment and duty-cycling in the scheduling phase of ET_3 [14]. The neighbour discovery phase and the registration phase are the same for PA_1, PA_2, APP_ 5 and APP 6 as the same coverage model (3D coverage model) of VSN has been used in all the approaches. ET_ 3 differs from $\mathrm{APP}_{-} 5$ and $\mathrm{APP} \_6$ in the registration phase and the scheduling phase while in the neighbour discovery phase, they are the same. The duty cycling phase/(sub-phase) of PA_1, $\mathrm{PA} \_2 /\left(\mathrm{APP}_{2} 5\right.$ and $\left.\mathrm{APP} \_6\right)$ is handled in a centralized manner. In $\mathrm{ET}_{-} 3$ a hybrid (combination of distributed and centralized) duty-cycling technique based on grids is adopted.

In $\mathrm{PA}_{-} 1, \mathrm{PA}_{-} 2, \mathrm{APP}_{-} 5$ and $\mathrm{APP}_{-} 6$ the collision among messages and consequently loss in messages is reduced by tunable MAC protocol which utilizes CSMA/CA for reducing the message collision. As a result, the BS receives all the messages from VSNs in the registration phase. The BS in PA_1, $\mathrm{PA}_{-} 2 /\left(\mathrm{APP}_{-} 5, \mathrm{APP}_{-} 6\right)$ sends a sleep message again using tunable $\mathrm{MAC}$ protocol for turning off $\mathrm{T}_{-}$N-Act_VSN ${ }_{\text {opt }}$ number of/(a set of) VSNs. This results in the minimization of Act_ VSN as observed from Fig. 3 and minimization of $\mathrm{E}_{T o t}$ as observed from Fig. 4 which leads to maximization of $\mathrm{E}_{\text {Res }}$ (as observed from Fig. 5) and in turn network lifetime (as observed from Fig. 7) both in $\mathrm{PA}_{-} 1$ and $\mathrm{PA} \_$. This also results in the reduction in Act_VSN, $\mathrm{E}_{\text {Tot }}$, Per_ $\mathrm{CoV}$ and an increase in $\mathrm{E}_{\text {Res }}$, network lifetime in the case of $\overline{\mathrm{APP}}{ }_{5}$ (for node density $>100$ ) and APP_6 in comparison to ET_3 as observed from Fig. 3, Fig. 4, Fig. 6, Fig. 5 and Fig. 7 respectively. The four BSs operate simultaneously in $\mathrm{APP}_{-} 6$. Hence, the $\mathrm{BS}$ in $\mathrm{APP}_{-} 6$ receives most of the 
request messages from the VSNs in the target area. This reduces Act_VSN, $\mathrm{E}_{\text {Tot }}$, Per_CoV and enhances $\mathrm{E}_{\text {Res }}$, network lifetime more in $\mathrm{APP} \_6$ than in APP_5 and ET_3. The minimization of Act_VSN both in PA_1 and PA_2 (Fig. 3) results in no reduction of Per_CoV from Init_CoV as observed from Fig. 6. Therefore, Per_ $\mathrm{CoV}$ is the highest in $\mathrm{PA}_{-} 1$ and $\mathrm{PA}_{-} 2$ and it is the same as Init_Ran.

No message-passing takes place in the duty cycling phase of PA_1 and $\mathrm{PA}$ 2. Therefore, $\mathrm{CM}$ OV of $\mathrm{PA} 1$ and $\mathrm{PA} 22$ is the least as observed from Table 2 and Table 3 . Act_ $\overline{\mathrm{VSN}}_{\text {opt }}$ in $\overline{\mathrm{PA}} \overline{\mathrm{A}}_{-}$is optimal (minimum) and Act_VSN $\mathrm{V}_{\text {opt }}$ in $\mathrm{PA} \_2$ is near-optimal. Therefore, Act_ $\mathrm{VSN}_{\text {opt }}$ and Energy $_{\text {Tot_opt }}$ in $\mathrm{PA}_{-} 1$ are lesser than Act_VSN $\mathrm{Vpt}_{\text {op }}$ and Energy Eot_opt $_{\text {in }}$ PA_2 as observed from Fig. 3 and Fig. 4 respectively. $\mathrm{E}_{\text {Res }}$ in $\mathrm{PA}_{-} 1$ is greater than $\mathrm{E}_{\text {Res }}$ in $\mathrm{PA} 2$ for the same reason as observed from Fig. 5. PA_2 being based on AGA produces very good results in terms of minimizing Act_VSN and $\mathrm{E}_{\text {Tot }}$, and maximizing $\mathrm{E}_{\text {Res }}$ and network lifetime while maintaining Per_CoV equal to Init_CoV compared to that obtained by using APP_5, APP_6 and ET_3 (as observed from Fig. 3, Fig. 4, Fig. 5, Fig. 7 and Fig. 6 respectively).

The group leader [13] in the grid sends a sleep message to the two VSNs belonging to the $\mathrm{q}^{\text {th }}$ grid having the highest and second-highest weight respectively in ET_3. The VSNs get the sleep message from the corresponding group leader and broadcast the SAM message [13] to their corresponding neighbours. There is a collision between the sleep messages and the SAM message although sleep messages don't collide with each other across the grids in the target area. This results in a loss of sleep message. The loss of sleep message owing to collision enhances with the enhancement of deployed VSNs in the target area. A huge number of VSNs having the highest or second-highest weight in several grids do not receive sleep messages from their corresponding group leader and consequently, those VSNs remain active although they fulfil the condition of redundant coverage [13, 14]. This enhances Act_VSN (Fig. 3), $\mathrm{E}_{\text {Tot }}$ (Fig. 4) and Per_CoV (Fig. 6) and decreases $\mathrm{E}_{\text {Res }}$ (Fig. 5) and network lifetime (Fig. 7 ) in $\mathrm{ET}_{-} 3$ compared to $\mathrm{APP} \_5$ (for node density $>100$ ).

\section{Conclusions}

In this paper, two advanced approaches, PA_1 and PA_2 have been proposed to minimize the number of active $3 \mathrm{D}$ video sensor nodes monitoring $2 \mathrm{D}$ target area without losing area coverage and ensuring network connectivity in the target area with randomly deployed VSNs. The total energy consumption by the video sensor nodes being proportional to the number of active video sensor nodes, PA_1 and PA_2 are designed for minimizing energy consumption. PA_1 produces the optimal value of energy consumption, while PA_2 produces a near-optimal value of energy consumption, subject to coverage and connectivity constraints. $\mathrm{APP}_{-} 5, \mathrm{APP}_{-} 6$, and $\mathrm{ET}_{-} 3$ are the existing state-of-the-art approaches with which $\mathrm{PA}_{-} \overline{1}$ and $\mathrm{PA}{ }_{-} 2$ are compared both 
with regard to energy consumption and area coverage. It is observed that both PA_1 and PA_2 produce much better results while minimizing energy consumption and also maintaining the initial coverage compared to APP_5, $\mathrm{APP}_{-} 6$ and $\mathrm{ET} \_3$.

A new approach can be developed in future to address the above-mentioned conflicting issues in the presence of heterogeneous $3 \mathrm{D}$ video sensor nodes where all video sensor nodes will have different communication and sensing ranges.

\section{Declaration of conflict of interest}

The authors proclaim that they have no knowledge of personal relationship or competing financial interests that could have appeared to inspire the work in this paper.

\section{Availability of Data}

The data underlying this article will be shared on reasonable request to the corresponding author.

\section{References}

[1] Bairagi, K., Mitra, S., Bhattacharya, U.: Coverage Aware Dynamic Scheduling Strategies for Wireless Video Sensor Nodes to Reduce Energy Consumption. 11th International Conference on Computing, Communication and Networking Technologies (ICCCNT), Kharagpur, India, 2020, pp. 1-7 (2020), IEEE, New Jersey, United States, doi: 10.1109/ICCCNT49239.2020.9225516

[2] Bairagi, K., Bhattacharya, U.: Resource Constrained Coverage Model of a Video Sensor Node to Reduce Energy Consumption. IEEE International Conference on Electrical, Computer and Communication Technologies (ICECCT), Coimbatore, India, 2019, pp. 1-7 (2019), IEEE, New Jersey, doi: 10.1109/ICECCT.2019.8869026

[3] Bendimerad, N., Kechar, B.: Rotational Wireless Video Sensor Networks with Obstacle Avoidance Capability for Improving Disaster Area Coverage. Journal of Information Processing Systems, vol. 11, no. 4, pp. 509-527 (2015), doi: 10.3745/JIPS.03.0034

[4] Bendimerad, N., Kechar, B.: Coverage enhancement with rotatable sensors in Wireless Video Sensor Networks for post-disaster management. 1st International Conference on Information and Communication Technologies for Disaster Management (ICT-DM), Algiers, pp. 1-7 (2014), IEEE, New Jersey, doi: 10.1109/ICT-DM.2014.6918584 
[5] Salim, Ahmed., Osamy, Walid., Khedr, Ahmed.: Effective Scheduling Strategy in Wireless Multimedia Sensor Networks for Critical Surveillance Applications. Applied Mathematics \& Information Sciences, vol. 12, pp. 101-111 (2018), doi: 10.18576/amis/120109

[6] Makhoul, A., Abdallah, Pham, C.: Dynamic Scheduling of Cover-Sets in Randomly Deployed Wireless Video Sensor Networks for Surveillance Applications. 2nd IFIP Wireless Days, pp. 1 - 6 (2009), IEEE, New Jersey, doi: 10.1109/WD.2009.5449700

[7] Ukani, V., Patel, K., Zaveri, T.: Computation of Coverage Backup Set for Wireless Video Sensor Network. IEEE Region 10 Symposium, Ahmedabad, pp. 37-40 (2015), IEEE, New Jersey, doi: 10.1109/TENSYMP.2015.23

[8] Benzerbadj, A., Kechar, B.: Redundancy and criticality based scheduling in wireless video sensor networks for monitoring critical areas. Procedia computer science (ELSEVIER) vol. 21, pp. 234-241 (2013)

[9] Ukani, V., Patel, K., Zaveri, T.: A Realistic Coverage Model with Backup Set Computation for Wireless Video Sensor Network. Nirma University Journal of Engineering and Technology, Vol. 4, No. 1, pp. 1-5 (2015)

[10] Integer programming. Accessed: June. 16, 2021 [online] Available: https://en.wikipedia.org/wiki/Integer_programming

[11] Mehboob, U., Qadir, J., Ali, S. et al.: Genetic algorithms in wireless networking: techniques, applications, and issues. Soft Comput 20, 2467-2501 (2016). https://doi.org/10.1007/s00500-016-2070-9

[12] Tian, J., Gao, M., Ge, G.: Wireless sensor network node optimal coverage based on improved genetic algorithm and binary ant colony algorithm. J Wireless Com Network 2016, 104 (2016) https://doi.org/10.1186/s13638016-0605-5

[13] Zhang, K., Chen, J., Shen, C., Chen, Y., Long, K., Aslam, B. U.: Node Scheduling Algorithm Based on Grid for Wireless Sensor Networks. 19th International Conference on Communication Technology (ICCT), pp. 987990 (2019), IEEE, New Jersey, doi: 10.1109/ICCT46805.2019.8947095

[14] Bairagi, K., Mitra, S., Bhattacharya, U.: Coverage Aware Scheduling Strategies for 3D Wireless Video Sensor Nodes to Enhance Network Lifetime. IEEE Access, vol. 9, pp. 124176-124199 (2021), doi: 10.1109/ACCESS.2021.3110271

[15] Wang, P., Dai, R., Akyildiz, I. F.: A differential coding-based scheduling framework for wireless multimedia sensor networks. IEEE Transactions on Multimedia, vol. 15, no. 3, April 2013, pp. 684-697 (2013), doi: 
10.1109/TMM.2012.2236304

[16] Yu, C., Sharma, G.: Camera scheduling and energy allocation for lifetime maximization in user-centric visual sensor networks. IEEE Transactions on Image Processing, vol. 19, no. 8, pp. 2042-2055 (Aug. 2010), doi: 10.1109/TIP.2010.2046794

[17] Jamshed, M. A., Khan, M. F., Rafique, K., Khan, M. I., Faheem, K., Shah, S. M., Rahim, A.: An energy efficient priority based wireless multimedia sensor node dynamic scheduler. $12^{\text {th }}$ International Conference on High-capacity Optical Networks and Enabling/Emerging Technologies (HONET), Islamabad, 2015, pp. 1-4 (2015), IEEE, New Jersey, doi: 10.1109/HONET.2015.7395435.

[18] Bhosale, V. D., Satao, R. A.: Lifetime maximization in mobile visual sensor network by priority assignment. International Conference on Control, Instrumentation, Communication and Computational Technologies (ICCICCT), Kumaracoil, 2015, pp. 695-698 (2015), IEEE, New Jersey, doi: 10.1109/ICCICCT.2015.7475368

[19] Khursheed, K., Imran, M., O'Nils M., Lawal, N.: Exploration of local and central processing for a wireless camera based sensor node. ICSES International Conference on Signals and Electronic Circuits, Gliwice, pp. 147-150 (2010), IEEE, New Jersey

[20] Ahn, Jun-Woo., Chang, Tai-Woo, Lee, Sung-Hee., Seo, Yong Won.: Two-phase algorithm for optimal camera placement. Scientific Programming (Hindawi), vol. 2016, ArticleID 4801784, 16 pages (2016), doi: $10.1155 / 2016 / 4801784$

[21] Fu, Y., Zhou, J., Deng, L.: Surveillance of a 2D Plane Area with 3D Deployed Cameras. Sensors (Basel, Switzerland), vol. 14, pp. 1988-2011 (2014), doi: 10.3390/s140201988

[22] Xu, Y., Jiao, W., Tian, M.: Energy-Efficient Connected-Coverage Scheme in Wireless Sensor Networks. Sensors, 20, 6127 (2020), https://doi.org/10.3390/s2021612

[23] Saadaldeen, Razan S.M., Ahmed, Yousif E.E., Osman, Abdalla A.: An Approach to Efficient Data Redundancy Reduction While Preserving the Full Coverage in a WSN. IRJET, Vol. 7, Issue 7, pp. 780-790 (July 2020)

[24] Qin, N., Chen, J.: An area coverage algorithm for wireless sensor networks based on differential evolution. International Journal of Distributed Sensor Networks, Vol. 14(8), pp. 1-11 (2018), https://doi.org/10.1177/1550147718796734 
[25] Dong, L., Tao, H., Doherty, W., Young, M.: A Sleep Scheduling Mechanism with PSO Collaborative Evolution for Wireless Sensor Networks. International Journal of Distributed Sensor Networks, Vol. 11(3) March 2015, pp. 1-12 (2015), doi: 10.1155/2015/517250

[26] Zhou, J., Xu, M., Lu, Yi., Yang, R.: Research on coverage control algorithm based on wireless sensor network. MATEC Web Conf., 309 (2020) 03003, EDP Sciences, France, doi: https://doi.org/10.1051/matecconf/202030903003

[27] Shanti D L., Prasanna, K.: Computational Intelligence based WSN lifetime extension with maximizing the disjoint Set K-Cover. Turkish Journal of Computer and Mathematics Education, Vol. 12, No. 11, pp. 3832-3849 (2021)

[28] Karp, B, Kung, H. T.: GPSR: greedy perimeter stateless routing for wireless networks. In: Proceedings of the 6th annual international conference on Mobile computing and networking (MobiCom '00), pp. 243-254 (2000), Association for Computing Machinery, New York, NY, USA, doi: $10.1145 / 345910.345953$

[29] Philips, T. K., Panwar, S. S., Tantawi, A. N.: Connectivity properties of a packet radio network model. IEEE Transactions on Information Theory, vol. 35, no. 5, pp. 1044-1047 (1989), doi: 10.1109/18.42219

[30] Mitchell, S., OSullivan, M., Dunning, I.: PuLP: A Linear Programming Toolkit for Python. The University of Auckland, Auckland, New Zealand (2011). Accessed: Jun. 16, 2021. [online]. Available: http://www.optimization-online.org/DB_FILE/2011/09/3178.pdf

[31] Pham, C.: A video sensor simulation model with OMNET ++ , Castalia Extension (2015). Accessed: Sep. 25, 2016. [online]. Available: http://cpham.perso.univ-pau.fr/WSN-MODEL/wvsn-castalia.html

[32] Pham, C.: A video sensor simulation model with OMNET ++ (2011). Accessed: Sep. 25, 206. [online]. Available: http://cpham.perso.univpau.fr/WSN-MODEL/wvsn.html

[33] Blank, J., Deb, K.: Pymoo: Multi-Objective Optimization in Python. IEEE Access, vol. 8, pp. 89497-89509 (2020), doi: 10.1109/ACCESS.2020.2990567 